Supporting Information for

\title{
Feet-to-Feet Connected Trisresorcinarenes
}

Daisuke Shimoyama, ${ }^{\dagger}$ Ryo Sekiya, ${ }^{+}$Hiroto Kudo, ${ }^{\ddagger}$ and Takeharu Haino ${ }^{*,+}$

${ }^{+}$Department of Chemistry, Graduate School of Science, Hiroshima University,1-3-1 Kagamiyama, Higashi-Hiroshima, Hiroshima, 739-8526 Japan, e-mail: haino@hiroshima-u.ac.jp

‡Department of Chemistry and Materials Engineering, Faculty of Chemistry, Materials and Bioengineering, Kansai University, 3-3-35 Yamate-cho, Suita, Osaka 564-8680 Japan

\section{Table of Contents}

\section{Experimental Section}

S3-6

Figure S1. ${ }^{1} \mathrm{H},{ }^{13} \mathrm{C}$ NMR spectra of compound 2 a. S7

Figure S2. ${ }^{1} \mathrm{H},{ }^{13} \mathrm{C}$ NMR spectra of compound $\mathbf{2 b}$. S8

Figure S3. ${ }^{1} \mathrm{H},{ }^{13} \mathrm{C}$ NMR spectra of compound $\mathbf{2 c}$. S9

Figure S4. ${ }^{1} \mathrm{H}$ NMR spectra of compound 1a. $\quad$ S10

$\begin{array}{lr}\text { Figure S5. }{ }^{1} \mathrm{H} \text { NMR spectra of compound } \mathbf{1 b} . & \text { S10 }\end{array}$

$\begin{array}{lr}\text { Figure S6. }{ }^{1} \mathrm{H} \text { NMR spectra of compound 1c. } & \text { S10 }\end{array}$

Figure S7. ${ }^{1} \mathrm{H},{ }^{13} \mathrm{C}$ and DEPT-135 NMR spectra of compound 3a. $\quad$ S11

Figure S8. ${ }^{1} \mathrm{H},{ }^{13} \mathrm{C}$ and DEPT-135 NMR spectra of compound $\mathbf{3 b}$. $\quad \mathrm{S} 12$

Figure S9. ${ }^{1} \mathrm{H},{ }^{13} \mathrm{C}$ and DEPT-135 NMR spectra of compound 3c. $\quad$ S13

Figure S10. ESI-Orbitrap-MS full spectra of 1,1,13,13-tetra(2,12-dihydroxyphenyl)tridecane.

Figure S11. ESI-Orbitrap-MS full spectra of 1,1,15,15-tetra(2,14-dihydroxyphenyl)pentadecane.

$\begin{array}{ll}\text { Figure S12. ESI-Orbitrap-MS full spectra of 3a. } & \text { S15 }\end{array}$

$\begin{array}{ll}\text { Figure S13. ESI-Orbitrap-MS full spectra of } \mathbf{3 b} . & \text { S15 }\end{array}$

$\begin{array}{ll}\text { Figure S14. ESI-Orbitrap-MS full spectra of 3c. } & \text { S16 }\end{array}$

$\begin{array}{ll}\text { Figure S15. 2D NOESY spectrum of 1a. } & \text { S17 }\end{array}$

$\begin{array}{ll}\text { Figure S16. 2D HSQC spectrum of 1a. } & \text { S17 }\end{array}$

$\begin{array}{ll}\text { Figure S17. 2D NOESY spectrum of } \mathbf{1 b} & \mathrm{S} 18\end{array}$

$\begin{array}{ll}\text { Figure S18. 2D HSQC spectrum of } \mathbf{1 b} & \text { S18 }\end{array}$

$\begin{array}{ll}\text { Figure S19. 2D NOESY spectrum of 1c. } & \text { S19 }\end{array}$ 
Figure S20. 2D HSQC spectrum of 1c.

Figure S21. Variable temperature ${ }^{1} \mathrm{H}$ NMR spectra of 3a. $\quad$ S20

$\begin{array}{ll}\text { Figure S22. Variable temperature }{ }^{1} \mathrm{H} \text { NMR spectra of } \mathbf{3 b} . & \text { S20 }\end{array}$

$\begin{array}{ll}\text { Figure S23. Variable temperature }{ }^{1} \mathrm{H} \text { NMR spectra of 3c. } & \text { S21 }\end{array}$

$\begin{array}{ll}\text { Figure S24. 2D NOESY spectrum of 3a. } & \text { S21 }\end{array}$

$\begin{array}{ll}\text { Figure S25. 2D HSQC spectrum of 3a. } & \text { S22 }\end{array}$

$\begin{array}{ll}\text { Figure S26. Selected regions of 2D HSQC spectrum of 3a. } & \text { S22 }\end{array}$

$\begin{array}{ll}\text { Figure S27. DQF-COSY spectrum of 3a. } & \text { S23 }\end{array}$

$\begin{array}{ll}\text { Figure S28. 2D NOESY spectrum of } \mathbf{3 b} & \text { S23 }\end{array}$

$\begin{array}{ll}\text { Figure S29. 2D HSQC spectrum of } \mathbf{3 b} & \text { S24 }\end{array}$

$\begin{array}{ll}\text { Figure S30. Selected regions of 2D HSQC spectrum of 3b. } & \text { S24 }\end{array}$

$\begin{array}{ll}\text { Figure S31. DQF-COSY spectrum of 3b. } & \text { S25 }\end{array}$

$\begin{array}{ll}\text { Figure S32. 2D NOESY spectrum of 3c. } & \text { S25 }\end{array}$

$\begin{array}{ll}\text { Figure S33. 2D HSQC spectrum of 3c. } & \text { S26 }\end{array}$

Figure S34. Selected regions of 2D HSQC spectrum of 3c. $\quad$ S26

$\begin{array}{lr}\text { Figure S35. DQF-COSY spectrum of 3c. } & \text { S27 }\end{array}$

$\begin{array}{ll}\text { Table S1. Crystallographic parameters. } & \text { S28 }\end{array}$

$\begin{array}{ll}\text { Figure S36. X-ray crystal structure of 3a. } & \text { S29 }\end{array}$

$\begin{array}{ll}\text { Figure S37. X-ray crystal structure of } \mathbf{3 b} . & \mathrm{S} 30\end{array}$

$\begin{array}{ll}\text { Figure S38. X-ray crystal structure of } \mathbf{3 c} \text { S31 } & \text { S3 }\end{array}$

Table S2. Dihedral angles of aliphatic methylene chains in the crystal structure of 3a. $\quad$ S32

Table S3. Dihedral angles of aliphatic methylene chains in the crystal structure of $\mathbf{3 b} . \quad$ S32

Table S4. Dihedral angles of aliphatic methylene chains in the crystal structure of $\mathbf{3 c} . \quad$ S33 


\section{Experimental Section}

General: All reagents and solvents were of the commercial reagent grade and were used without further purification except where noted. ${ }^{1} \mathrm{H}$ and ${ }^{13} \mathrm{C}$ NMR spectra were recorded on a VARIAN Mercury 300 spectrometer or a JEOL ECA500 spectrometer. Chemical shifts are quoted as parts per million (ppm) relative to chloroform (chloroform- $d_{1}, \delta=7.26 \mathrm{ppm}$ for ${ }^{1} \mathrm{H}$ and $77.0 \mathrm{ppm}$ for ${ }^{13} \mathrm{C}$ ), tetrachloroethane (tetrachloroethane- $d_{2}, \delta=6.00 \mathrm{ppm}$ for ${ }^{1} \mathrm{H}$ and $74.0 \mathrm{ppm}$ for ${ }^{13} \mathrm{C}$ ), and dimethylsulfoxide (dimethylsulfoxide- $d_{6}, \delta=2.46 \mathrm{ppm}$ for ${ }^{1} \mathrm{H}$ and $39.5 \mathrm{ppm}$ for ${ }^{13} \mathrm{C}$ ). IR spectra were recorded on a JASCO FT/IR-4600 spectrometer. IR spectra were recorded on JASCO FT/IR-420S spectrometer. APCI-Mass and ESI-Mass spectra were recorded on Thermo Scientific LTQ Orbitrap XL hybrid FTMS.

\section{X-ray Crystallography}

X-ray quality single crystals of 3a-c were grown from benzene solutions by slow evaporation of hexane at room temperature. X-ray crystallographic data were collected on a Bruker SMART AEPX II ULTRA CCD diffractometer. The crystals were irradiation using Mo-K $\alpha$ radiation $(\lambda=0.71073 \AA)$ at $123 \mathrm{~K}$. The crystal structures were solved by direct method using the SHELXS-2013 program and refined by successive differential Fourier syntheses and full-matrix least-squares procedures using the SHELXL-2013 program. Anisotropic thermal factors were applied for all atoms except for the hydrogen atoms. The hydrogen atoms were generated geometrically. Diffuse electron densities arising from the disordered solvents in 3a-c were treated with the SQUEEZE routine in the PLATON program. A summary of data collection and structure refinement details is provided in Table S1.

1,5-di(1,3-dioxolan-2-yl)pentane 2a. A mixture of 1,1,7,7-tetramethoxyheptane (20.0 g, 90.8 mmol), ethylene glycol ( $100 \mathrm{~mL}, 1.79 \mathrm{~mol})$, and pyridinium $p$-toluenesulfonate $(35.0 \mathrm{~g}, 139 \mathrm{mmol})$ in distilled dichloromethane $(230 \mathrm{~mL})$ was stirred at room temperature. After stirred for $15 \mathrm{~h}$, the mixture was neutralized to $\mathrm{pH}$ 7-8 with sodium hydrogen carbonate and extracted with ethyl acetate. The organic layer was dried over sodium sulfate, and the solvent was removed in vacuo. The crude product was purified by column chromatography (silica gel, hexane/ethyl acetate) to give $\mathbf{2 a}$ as a colorless oil (15.5 g, 78\%). ' ${ }^{1} \mathrm{H}$ NMR (300 MHz, chloroform- $\left.d_{1}\right): \delta 4.84(\mathrm{t}, J=4.8 \mathrm{~Hz}, 2 \mathrm{H}), 3.90$ (AA'BB', 8H), $1.66(\mathrm{~m}$, 4H), $1.40(\mathrm{~m}, 6 \mathrm{H}) \mathrm{ppm} ;{ }^{13} \mathrm{C}\left\{{ }^{1} \mathrm{H}\right\}$ NMR (75 MHz, chloroform- $\left.d_{1}\right): \delta 104.7,65.0,33.9,29.6,24.1 \mathrm{ppm}$; FTIR-ATR(neat): $v$ 2947, 2925, 2880, 2863, 1464, $1150 \mathrm{~cm}^{-1}$; HRMS (APCI/Orbitrap) m/z: [M + H] ${ }^{+}$ 
Calcd for $\mathrm{C}_{11} \mathrm{H}_{21} \mathrm{O}_{4}$ 217.1434; Found 217.1435 (error $0.46 \mathrm{ppm}$ ).

1,7-di(1,3-dioxolan-2-yl)heptane 2b. A mixture of 1,1,9,9-tetramethoxynonane (5.20 g, 21.3 mmol), ethylene glycol $(23 \mathrm{~mL}, 412 \mathrm{mmol})$, and pyridinium $p$-toluenesulfonate $(8.00 \mathrm{~g}, 31.8 \mathrm{mmol})$ in distilled dichloromethane $(52 \mathrm{~mL})$ was stirred at room temperature. After stirred for $15 \mathrm{~h}$, the mixture was neutralized to $\mathrm{pH}$ 7-8 with sodium hydrogen carbonate and extracted with ethyl acetate. The organic layer was dried over sodium sulfate, and the solvent was removed in vacuo. The crude product was purified by column chromatography (silica gel, hexane/ethyl acetate) to give $\mathbf{2} \mathbf{b}$ as a colorless oil (4.08 g, 78\%). 'H NMR (300 MHz, chloroform- $\left.d_{1}\right): \delta 4.84(\mathrm{t}, J=4.9 \mathrm{~Hz}, 2 \mathrm{H}), 3.90$ (AA'BB', 8H), $1.64(\mathrm{~m}, 4 \mathrm{H}), 1.32(\mathrm{~m}, 10 \mathrm{H}) \mathrm{ppm} ;{ }^{13} \mathrm{C}\left\{{ }^{1} \mathrm{H}\right\}$ NMR $\left(75 \mathrm{MHz}\right.$, chloroform- $\left.d_{1}\right): \delta 104.865 .034 .0$ 29.6, 29.6 24.2 ppm; FTIR-ATR(neat): $v$ 2928, 2879, 2857, $14671151 \mathrm{~cm}^{-1}$; HRMS (APCI/Orbitrap) m/z: $[\mathrm{M}+\mathrm{H}]^{+}$Calcd for $\mathrm{C}_{13} \mathrm{H}_{25} \mathrm{O}_{4}$ 245.1747; Found 245.1747 (error 0.04 ppm).

1,9-di(1,3-dioxolan-2-yl)nonane 2c. A mixture of 1,1,11,11-tetramethoxyundecane (5.42 g, 19.9 mmol), ethylene glycol (22 mL, $394 \mathrm{mmol})$, and pyridinium $p$-toluenesulfonate $(7.50 \mathrm{~g}, 29.8 \mathrm{mmol})$ in distilled dichloromethane $(50 \mathrm{~mL})$ was stirred at room temperature. After stirred for $15 \mathrm{~h}$, the mixture was neutralized to $\mathrm{pH}$ 7-8 with sodium hydrogen carbonate and extracted with ethyl acetate. The organic layer was dried over sodium sulfate, and the solvent was removed in vacuo. The crude product was purified by column chromatography (silica gel, hexane/ethyl acetate) and recrystallized from hexane to give $2 \mathbf{c}$ as a white solid (4.37 g, 81\%). M.p. 36-37 ${ }^{\circ} \mathrm{C}$; ${ }^{1} \mathrm{H}$ NMR (300 MHz, chloroform$\left.d_{1}\right): \delta 4.83(\mathrm{t}, J=4.9 \mathrm{~Hz}, 2 \mathrm{H}), 3.89\left(\mathrm{AA}^{\prime} \mathrm{BB} ', 8 \mathrm{H}\right), 1.65(\mathrm{~m}, 4 \mathrm{H}), 1.27(\mathrm{~m}, 14 \mathrm{H}) \mathrm{ppm} ;{ }^{13} \mathrm{C}\left\{{ }^{1} \mathrm{H}\right\} \mathrm{NMR}$ (75 MHz, chloroform- $d_{1}$ ): $\delta$ 104.8, 65.0, 34.0, 29.7, 29.6, 29.5, 24.2 ppm; FTIR-ATR(neat): $v$ 2946, 2926, 2883, 2854, 1465, $1152 \mathrm{~cm}^{-1}$; HRMS (APCI/Orbitrap) m/z: $[\mathrm{M}+\mathrm{H}]^{+}$Calcd for $\mathrm{C}_{15} \mathrm{H}_{29} \mathrm{O}_{4}$ 273.2060; Found 273.2061 (error 0.37 ppm).

Trisresorcinarene 1a. A mixture of resorcinol (2.56 g, $23.2 \mathrm{mmol})$ and 1,5-di(1,3-dioxolan-2yl)pentane (2a) (1.26 g, $5.83 \mathrm{mmol})$ in $n$-propanol (7 mL) and conc. $\mathrm{HCl}(1.9 \mathrm{~mL})$ was stirred for 3 days at $100{ }^{\circ} \mathrm{C}$ with the use of an oil bath. The crude product was filtered, washed with water and dried under vacuum to give 1a as an orange solid (1.26 g). M.p. $>300{ }^{\circ} \mathrm{C} ;{ }^{1} \mathrm{H}$ NMR $(500 \mathrm{MHz}$, dimethylsulfoxide- $\left.d_{6}, 80^{\circ} \mathrm{C}\right): \delta 8.94(\mathrm{~s}, 12 \mathrm{H}), 8.52(\mathrm{~s}, 12 \mathrm{H}), 7.16(\mathrm{~s}, 6 \mathrm{H}), 6.88(\mathrm{~s}, 6 \mathrm{H}), 6.22(\mathrm{~s}, 6 \mathrm{H})$, $6.05(\mathrm{~s}, 6 \mathrm{H}), 4.14(\mathrm{~m}, 12 \mathrm{H}), 2.33(\mathrm{~m}, 12 \mathrm{H}) 1.70(\mathrm{~m}, 12 \mathrm{H}), 1.39-0.90(\mathrm{~m}, 36 \mathrm{H}) \mathrm{ppm}$; HRMS (ESI/Orbitrap) m/z: [M - 2H] ${ }^{2-}$ Calcd for $\mathrm{C}_{114} \mathrm{H}_{118} \mathrm{O}_{24}$ 935.4012; Found 935.4004 (error 0.86 ppm). 
Trisresorcinarene 1b. A mixture of resorcinol (700 mg, $6.36 \mathrm{mmol}$ ) and 1,7-di(1,3-dioxolan-2yl)pentane (2b) (390 mg, $1.60 \mathrm{mmol})$ in $n$-propanol (1.9 mL) and conc. $\mathrm{HCl}(0.51 \mathrm{~mL})$ was stirred for 3 days at $100{ }^{\circ} \mathrm{C}$ with the use of an oil bath. The crude product was filtered, washed with water and dried under vacuum to give $\mathbf{1 b}$ as an orange solid (489 mg). M.p. $>300{ }^{\circ} \mathrm{C} ;{ }^{1} \mathrm{H}$ NMR $(500 \mathrm{MHz}$, dimethylsulfoxide- $\left.d_{6}, 80^{\circ} \mathrm{C}\right): \delta 9.10-8.47(\mathrm{~m}, 24 \mathrm{H}), 7.53-6.92(\mathrm{~m}, 12 \mathrm{H}), 6.21-6.11(\mathrm{~m}, 12 \mathrm{H}), 4.16$ $(\mathrm{m}, 12 \mathrm{H}), 1.48-0.86(\mathrm{~m}, 84 \mathrm{H}) \mathrm{ppm}$; HRMS (ESI/Orbitrap) m/z: $[\mathrm{M}-2 \mathrm{H}]^{2-}$ Calcd for $\mathrm{C}_{126} \mathrm{H}_{142} \mathrm{O}_{24}$ 1019.4951; Found 1019.4936 (error 1.5 ppm).

Trisresorcinarene 1c. A mixture of resorcinol (2.03 g, $18.5 \mathrm{mmol})$ and 1,9-di(1,3-dioxolan-2yl)nonane (2c) (1.26 g, $4.63 \mathrm{mmol})$ in $n$-propanol $(5.5 \mathrm{~mL})$ and conc. $\mathrm{HCl}(1.5 \mathrm{~mL})$ was stirred for 3 days at $100{ }^{\circ} \mathrm{C}$ with the use of an oil bath. The crude product was filtered, washed with water and dried under vacuum to give 1c as an orange solid (679 mg). M.p. $>300{ }^{\circ} \mathrm{C}$; ${ }^{1} \mathrm{H}$ NMR $(500 \mathrm{MHz}$, dimethylsulfoxide- $\left.d_{6}, 80^{\circ} \mathrm{C}\right): \delta 8.88(\mathrm{~s}, 12 \mathrm{H}), 8.70(\mathrm{~s}, 12 \mathrm{H}), 7.23(\mathrm{~s}, 6 \mathrm{H}), 7.13(\mathrm{~s}, 6 \mathrm{H}), 6.10(\mathrm{~s}, 6 \mathrm{H})$, $6.08(\mathrm{~s}, 6 \mathrm{H}), 4.27(\mathrm{~m}, 12 \mathrm{H}), 2.52(\mathrm{~m}, 12 \mathrm{H}), 1.67(\mathrm{~m}, 12 \mathrm{H}), 1.39-0.90(\mathrm{~m}, 84 \mathrm{H}) \mathrm{ppm}$; HRMS (ESI/Orbitrap) m/z: [M - 2H] $]^{2-}$ Calcd for $\mathrm{C}_{138} \mathrm{H}_{166} \mathrm{O}_{24}$ 1103.5890; Found 1103.5885 (error 0.45 ppm).

Trisresorcinarene 3a. Trisresorcinarene 1a (1.26 g) was dissolved in dichloromethane (30 mL), cooled to $0{ }^{\circ} \mathrm{C}$ and $\mathrm{NEt}_{3}(2.70 \mathrm{~mL}, 19.4 \mathrm{mmol})$ was added followed by dropwise addition of pivaloyl chloride (1.60 mL, $13.0 \mathrm{mmol})$ and DMAP (7 mg, cat.). The solution was warmed to room temperature stirred for $12 \mathrm{~h}$, the quenched by the caution addition of sat. aq $\mathrm{NH}_{4} \mathrm{Cl}$, washed with brine. The organic layer was dried over sodium sulfate, and the solvent was removed in vacuo. The crude product was purified by column chromatography (silica gel, benzene/ethyl acetate) and recrystallized from benzene/hexane to give 3a as white solid $\left(1.13 \mathrm{~g}, 30 \%\right.$, 2steps). M.p. $>300{ }^{\circ} \mathrm{C} ;{ }^{1} \mathrm{H} \mathrm{NMR}(500 \mathrm{MHz}$, tetrachloroethane- $\left.d_{2}\right): \delta 7.23(\mathrm{~s}, 6 \mathrm{H}), 7.06(\mathrm{~s}, 6 \mathrm{H}), 6.48(\mathrm{~s}, 6 \mathrm{H}), 5.93(\mathrm{~s}, 6 \mathrm{H}), 4.27(\mathrm{~m}, 12 \mathrm{H}), 1.82(\mathrm{~m}$, $12 \mathrm{H}), 1.55(\mathrm{~m}, 12 \mathrm{H}), 1.39(\mathrm{~s}, 108 \mathrm{H}), 1.15(\mathrm{~s}, 108 \mathrm{H}), 1.40-1.10(\mathrm{~m}, 36 \mathrm{H}) \mathrm{ppm} ;{ }^{13} \mathrm{C}\left\{{ }^{1} \mathrm{H}\right\} \mathrm{NMR}(125$ $\mathrm{MHz}$, tetrachloroethane- $\left.d_{2}\right): \delta 176.1,175.8,148.5,144.6,136.2,128.7,125.4,124.5,116.4,115.8$, 39.2, 39.0, 38.4, 37.1, 34.2, 28.1, 27.3, 26.9 ppm; FTIR-ATR(neat): $v$ 2974, 2935, 287317511480 $\mathrm{cm}^{-1}$; HRMS (ESI/Orbitrap) m/z: $\left[\mathrm{M}+\mathrm{Na}+\mathrm{NH}_{4}\right]^{2+}$ Calcd for $\mathrm{C}_{234} \mathrm{H}_{316} \mathrm{O}_{48} \mathrm{NNa}$ 1965.6102; Found 1965.6118 (error $0.81 \mathrm{ppm})$.

Trisresorcinarene 3b. Trisresorcinarene $\mathbf{1 b}(489 \mathrm{mg})$ was dissolved in DMF $(25 \mathrm{~mL})$, cooled to $0{ }^{\circ} \mathrm{C}$ was added followed by dropwise addition of Di-tert-butyl Dicarbonate $(3.15 \mathrm{~g}, 14.4 \mathrm{mmol})$ and DMAP (7 mg, cat.). The solution was warmed to room temperature stirred for $12 \mathrm{~h}$, the mixture was extracted 
with chloroform. The organic layer was dried over sodium sulfate, and the solvent was removed in vacuo. The crude product was purified by column chromatography (silica gel, benzene/ethyl acetate) and recrystallized from benzene/hexane to give $3 \mathbf{b}$ as white solid (560 mg, 47\%, 2steps). M.p. $290{ }^{\circ} \mathrm{C}$ (decomp.); ${ }^{1} \mathrm{H}$ NMR (500 MHz, chloroform- $\left.d_{1}\right): \delta 7.05$ (s, 6H), 6.95 (s, 6H), $6.76(\mathrm{~s}, 6 \mathrm{H}), 6.48(\mathrm{~s}, 6 \mathrm{H})$, $4.30(\mathrm{~m}, 12 \mathrm{H}), 1.90(\mathrm{~m}, 12 \mathrm{H}), 1.74(\mathrm{~m}, 12 \mathrm{H}), 1.49(\mathrm{~s}, 108 \mathrm{H}), 1.42(\mathrm{~s}, 108 \mathrm{H}), 1.31-1.14(\mathrm{~m}, 60 \mathrm{H})$ ppm; ${ }^{13} \mathrm{C}\left\{{ }^{1} \mathrm{H}\right\}$ NMR $\left(125 \mathrm{MHz}\right.$, chloroform- $\left.d_{1}\right): \delta 151.7,151.1,148.0,146.4,134.6,131.3,125.8$, 125.5, 117.0, 116.1 , 82.8, 36.3, 35.8, 31.1, 29.8, 29.6, 27.8, 27.7 ppm; FTIR-ATR(neat): $v 29802931$ $285717521370 \mathrm{~cm}^{-1}$; HRMS (ESI/Orbitrap) m/z: $\left[\mathrm{M}+\mathrm{Na}+\mathrm{NH}_{4}\right]^{2+}$ Calcd for $\mathrm{C}_{246} \mathrm{H}_{340} \mathrm{O}_{72} \mathrm{NNa}$ 2241.6431; Found 2241.6434 (error 0.13 ppm).

Trisresorcinarene 3c. Trisresorcinarene 1c $(679 \mathrm{mg})$ was dissolved in dichloromethane $(30 \mathrm{~mL})$, cooled to $0{ }^{\circ} \mathrm{C}$ and $\mathrm{NEt}_{3}(2.3 \mathrm{~mL}, 16.5 \mathrm{mmol})$ was added followed by dropwise addition of pivaloyl chloride (1.35 mL, $11.1 \mathrm{mmol})$ and DMAP (6 mg, cat.). The solution was warmed to room temperature stirred for $12 \mathrm{~h}$, the quenched by the caution addition of sat. aq $\mathrm{NH}_{4} \mathrm{Cl}$, washed with brine. The organic layer was dried over sodium sulfate, and the solvent was removed in vacuo. The crude product was purified by column chromatography (silica gel, benzene/ethyl acetate) and recrystallized from benzene/hexane to give $3 \mathrm{c}$ as white solid $\left(1.23 \mathrm{~g}, 38 \%\right.$, 2steps). M.p. $>300{ }^{\circ} \mathrm{C} ;{ }^{1} \mathrm{H}$ NMR $(500 \mathrm{MHz}$, chloroform- $\left.d_{1}\right): \delta 7.30(\mathrm{~s}, 6 \mathrm{H}), 7.01(\mathrm{~s}, 6 \mathrm{H}), 6.58(\mathrm{~s}, 6 \mathrm{H}), 5.98(\mathrm{~s}, 6 \mathrm{H}), 4.19(\mathrm{~m}, 12 \mathrm{H}), 1.88(\mathrm{~m}, 12 \mathrm{H})$, $1.66(\mathrm{~m}, 12 \mathrm{H}), 1.37$ (s, 108H), $1.13(\mathrm{~s}, 108 \mathrm{H}), 1.40-1.10(\mathrm{~m}, 84 \mathrm{H}) \mathrm{ppm} ;{ }^{13} \mathrm{C}\left\{{ }^{1} \mathrm{H}\right\} \mathrm{NMR}(125 \mathrm{MHz}$, chloroform- $\left.d_{1}\right): \delta 176.2,176.0,148.7,145.8,134.6,129.2,127.4,126.0,116.6,116.0,39.5,39.1,38.2$, 34.9, 30.9, 30.9, 29.4, 28.5, 27.4, 27.1 ppm; FTIR-ATR(neat): $v 29782930286917511479 \mathrm{~cm}^{-1}$; HRMS (ESI/Orbitrap) m/z: $\left[\mathrm{M}+2 \mathrm{NH}_{4}\right]^{2+}$ Calcd for $\mathrm{C}_{258} \mathrm{H}_{368} \mathrm{O}_{48} \mathrm{~N}_{2} 2131.3203$; Found 2131.3226 (error $1.1 \mathrm{ppm})$. 

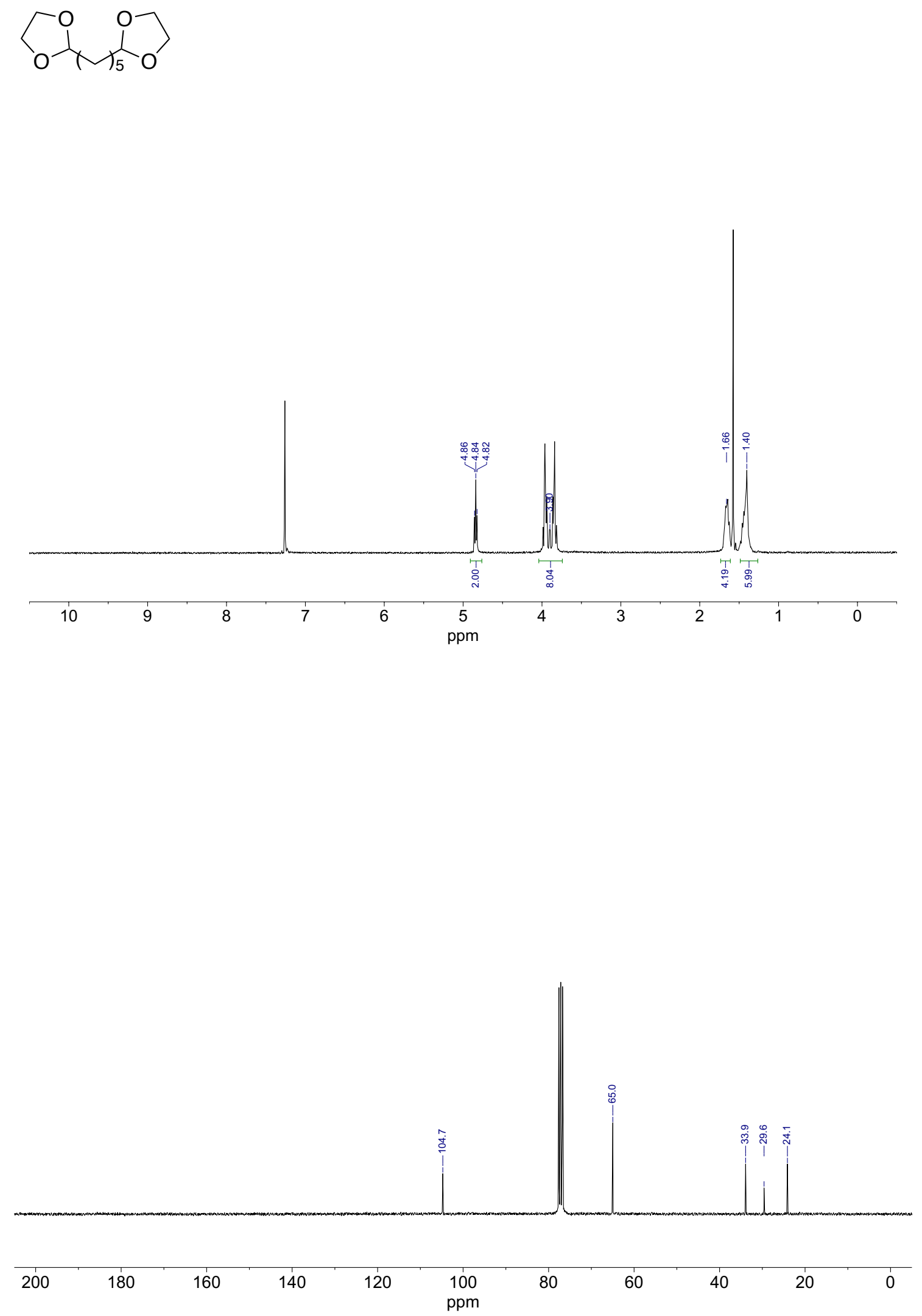

Figure S1. ${ }^{1} \mathrm{H}$ and ${ }^{13} \mathrm{C}$ NMR spectra of $\mathbf{2 a}$ in chloroform- $d_{1}$. 

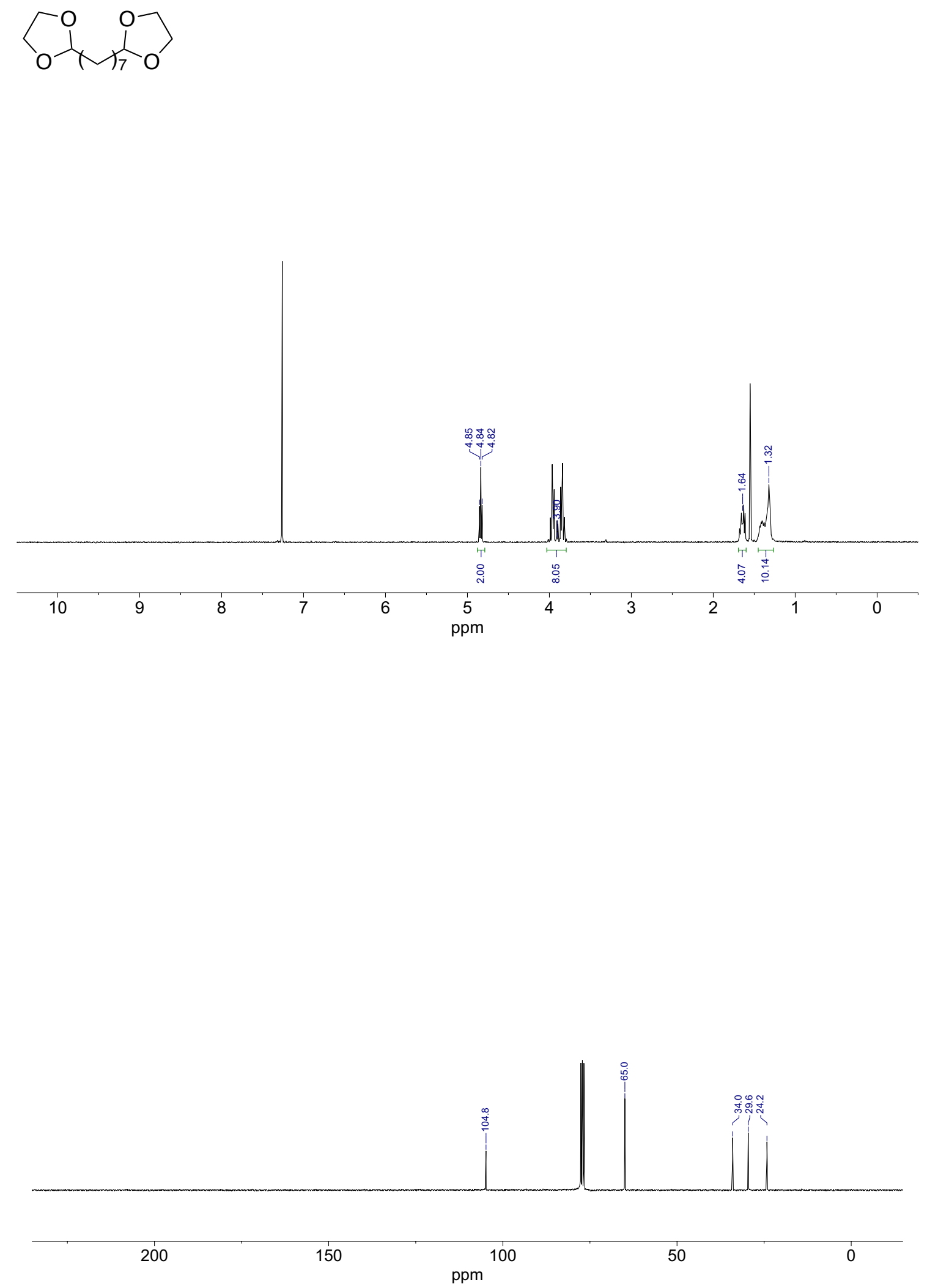

Figure S2. ${ }^{1} \mathrm{H}$ and ${ }^{13} \mathrm{C}$ NMR spectra of $\mathbf{2 b}$ in chloroform- $d_{1}$. 

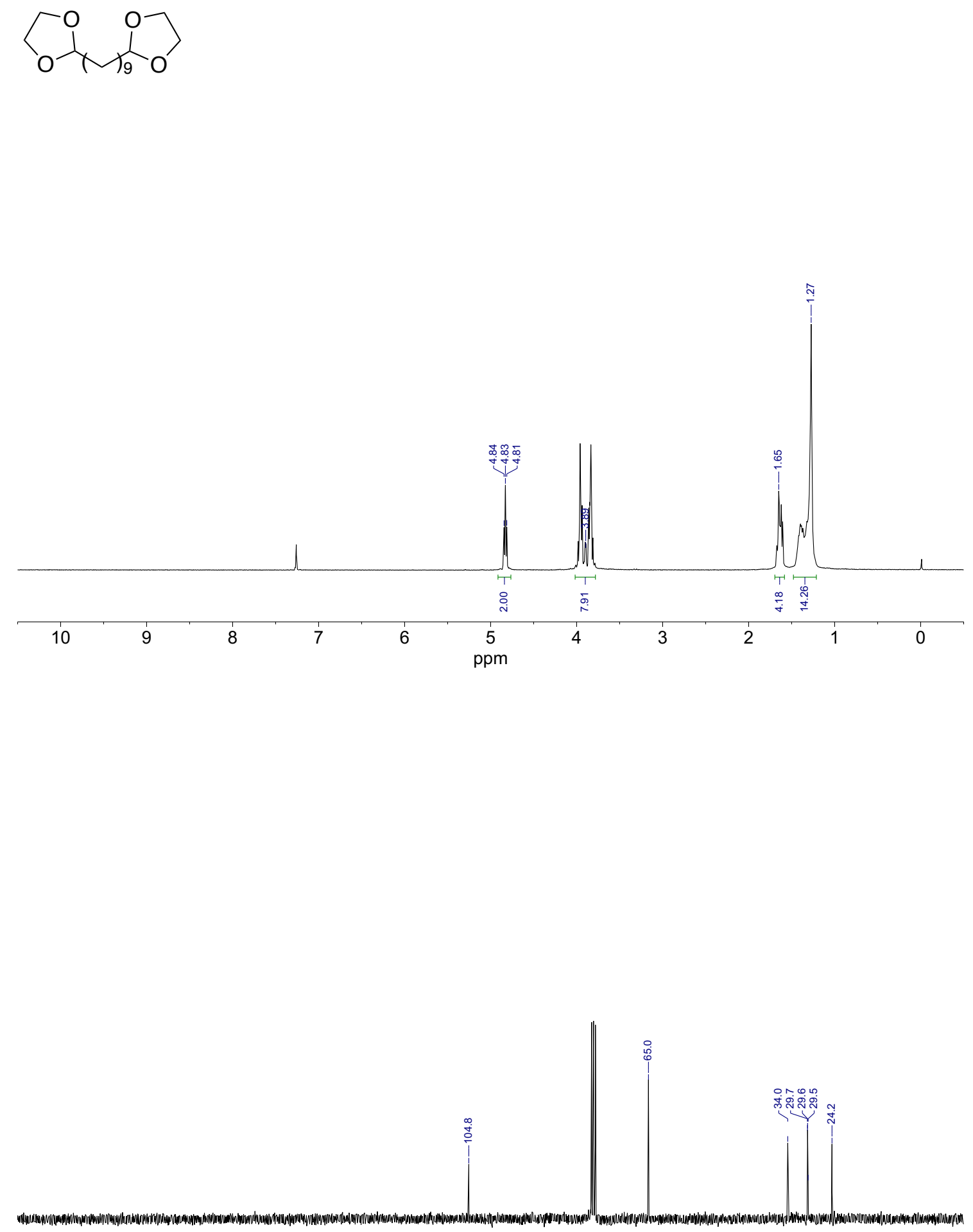

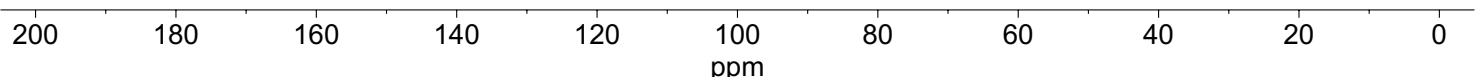

Figure S3. ${ }^{1} \mathrm{H}$ and ${ }^{13} \mathrm{C}$ NMR spectra of $2 \mathrm{c}$ in chloroform- $d_{1}$. 


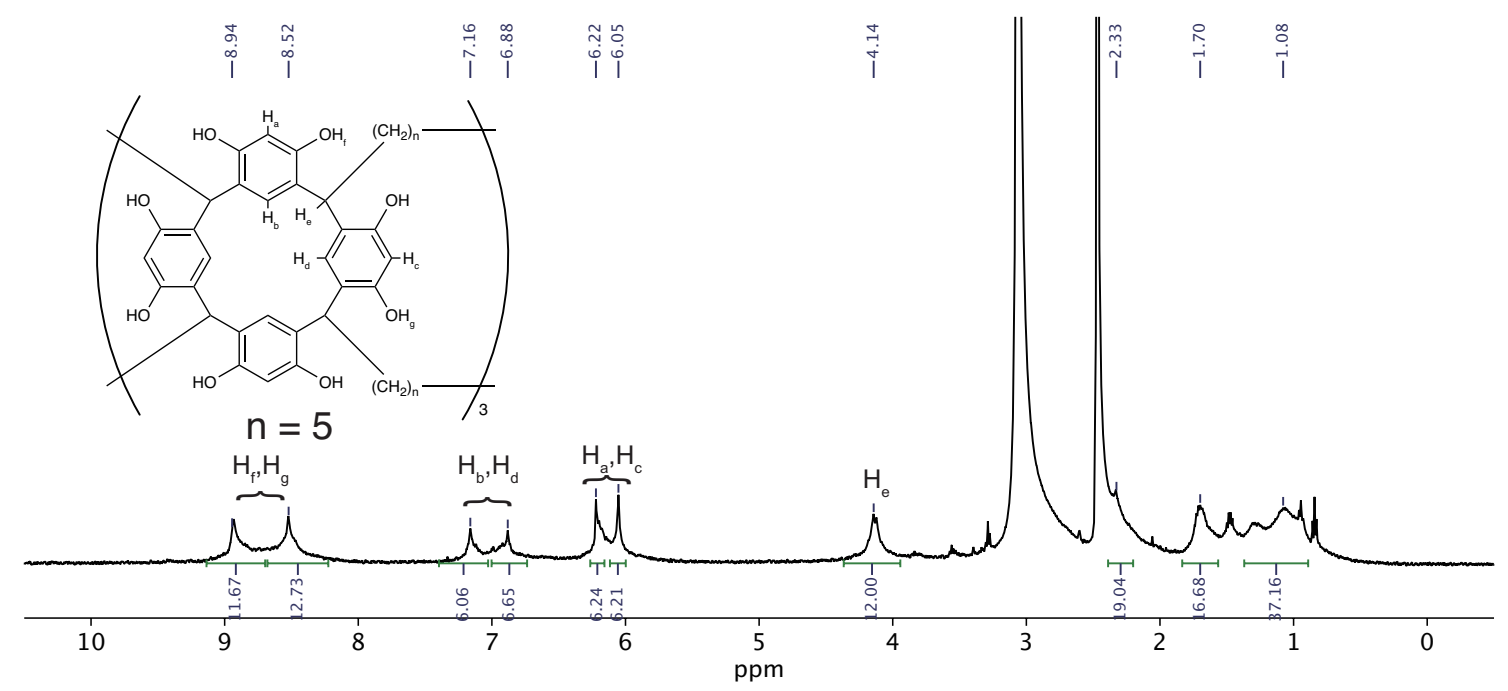

Figure S4. ${ }^{1} \mathrm{H}$ NMR spectrum of $\mathbf{1 a}\left(500 \mathrm{MHz}, 80^{\circ} \mathrm{C}\right)$ in dimethylsulfoxide- $d_{6}$.

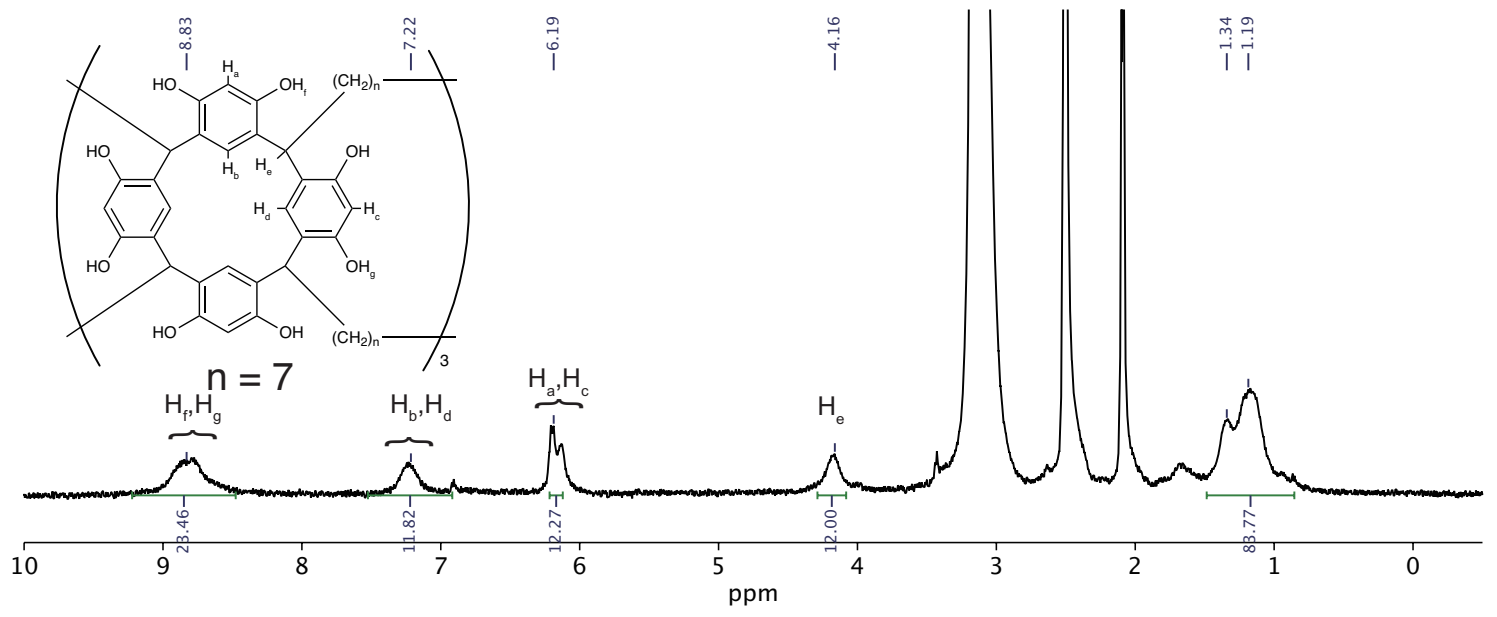

Figure S5. ${ }^{1} \mathrm{H}$ NMR spectrum of $\mathbf{1 b}\left(500 \mathrm{MHz}, 80^{\circ} \mathrm{C}\right)$ in dimethylsulfoxide- $d_{6}$.

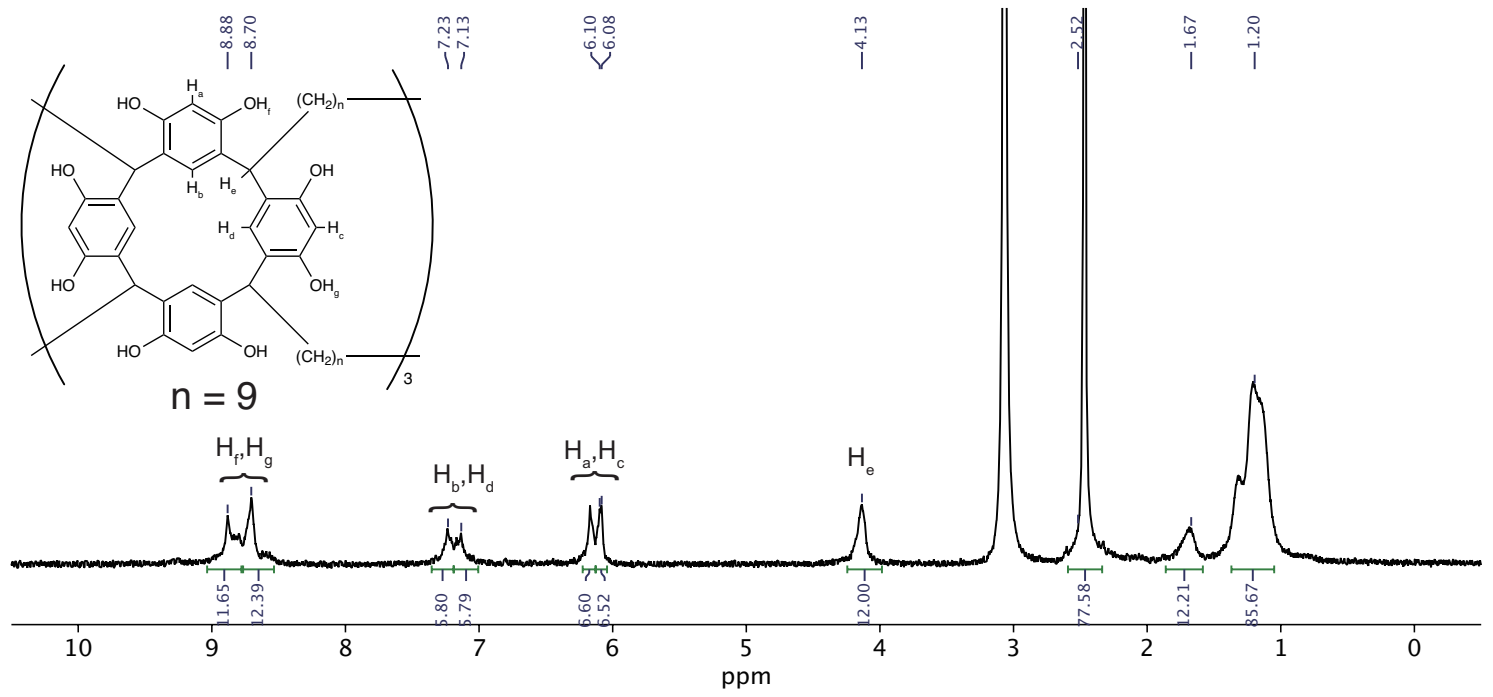

Figure S6. ${ }^{1} \mathrm{H}$ NMR spectrum of $1 \mathrm{c}\left(500 \mathrm{MHz}, 80^{\circ} \mathrm{C}\right)$ in dimethylsulfoxide- $d_{6}$. 

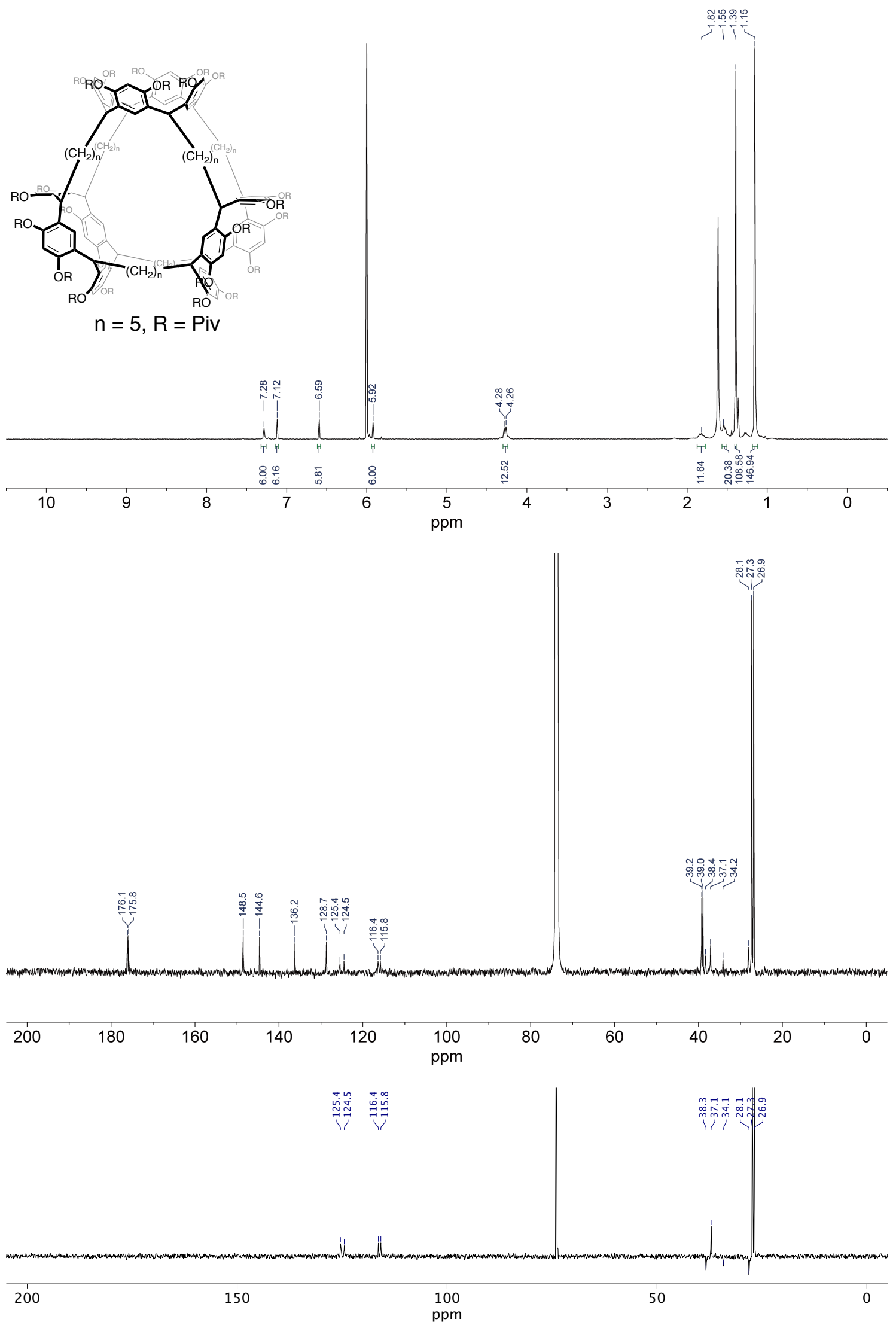

Figure S7. ${ }^{1} \mathrm{H},{ }^{13} \mathrm{C}$ and DEPT-135 NMR spectra of 3a in tetrachloroethane- $d_{2}$. 

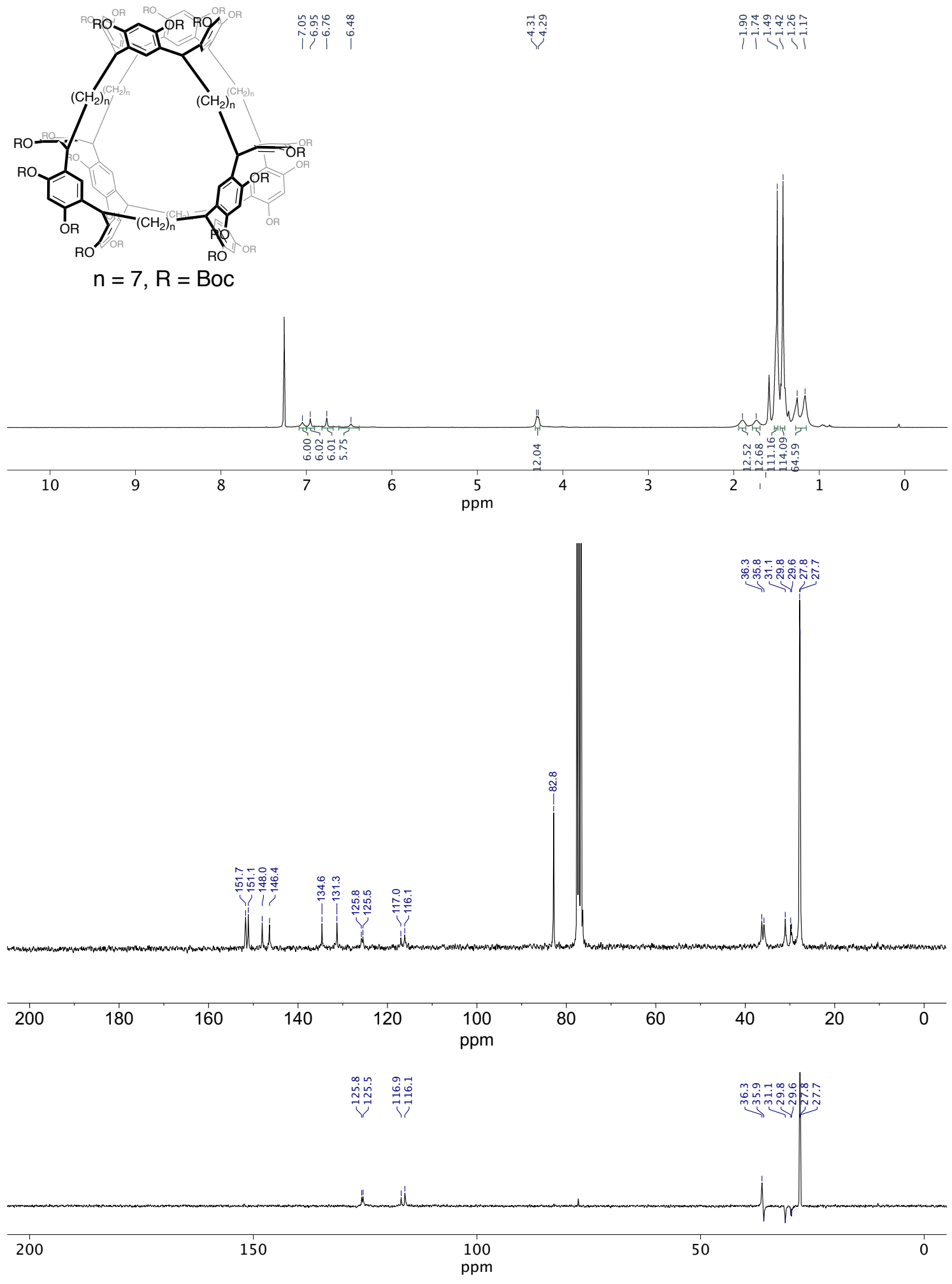

Figure S8. ${ }^{1} \mathrm{H},{ }^{13} \mathrm{C}$ NMR and DEPT-135 spectra of $\mathbf{3 b}$ in chloroform- $d_{1}$. 

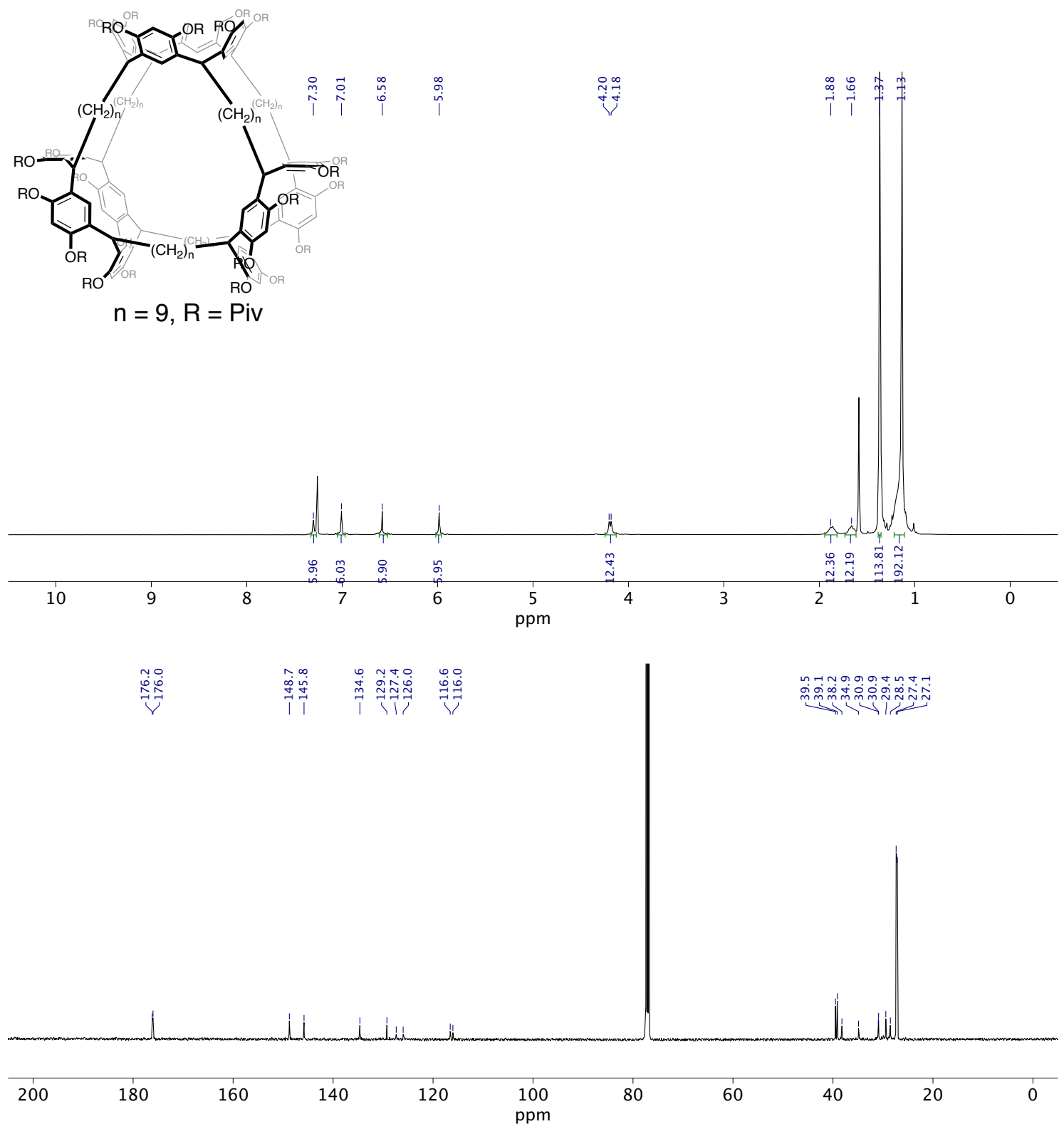

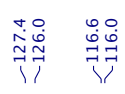

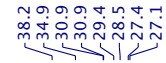

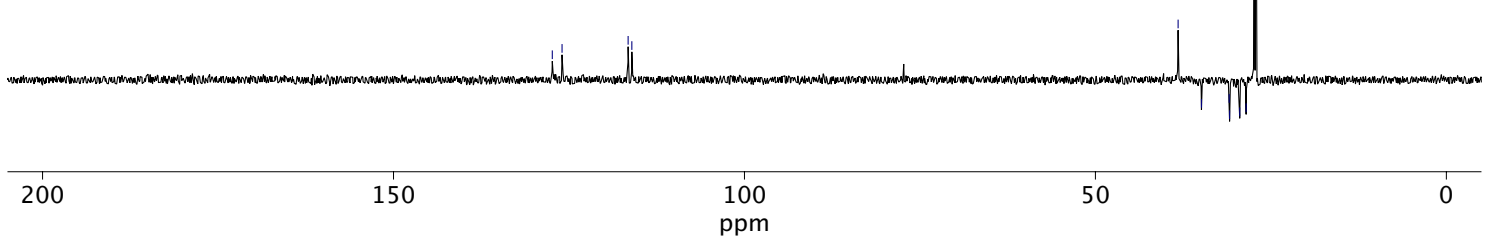

Figure S9. ${ }^{1} \mathrm{H},{ }^{13} \mathrm{C}$ NMR and DEPT-135 spectra of $\mathbf{3 c}$ in chloroform- $d_{1}$. 


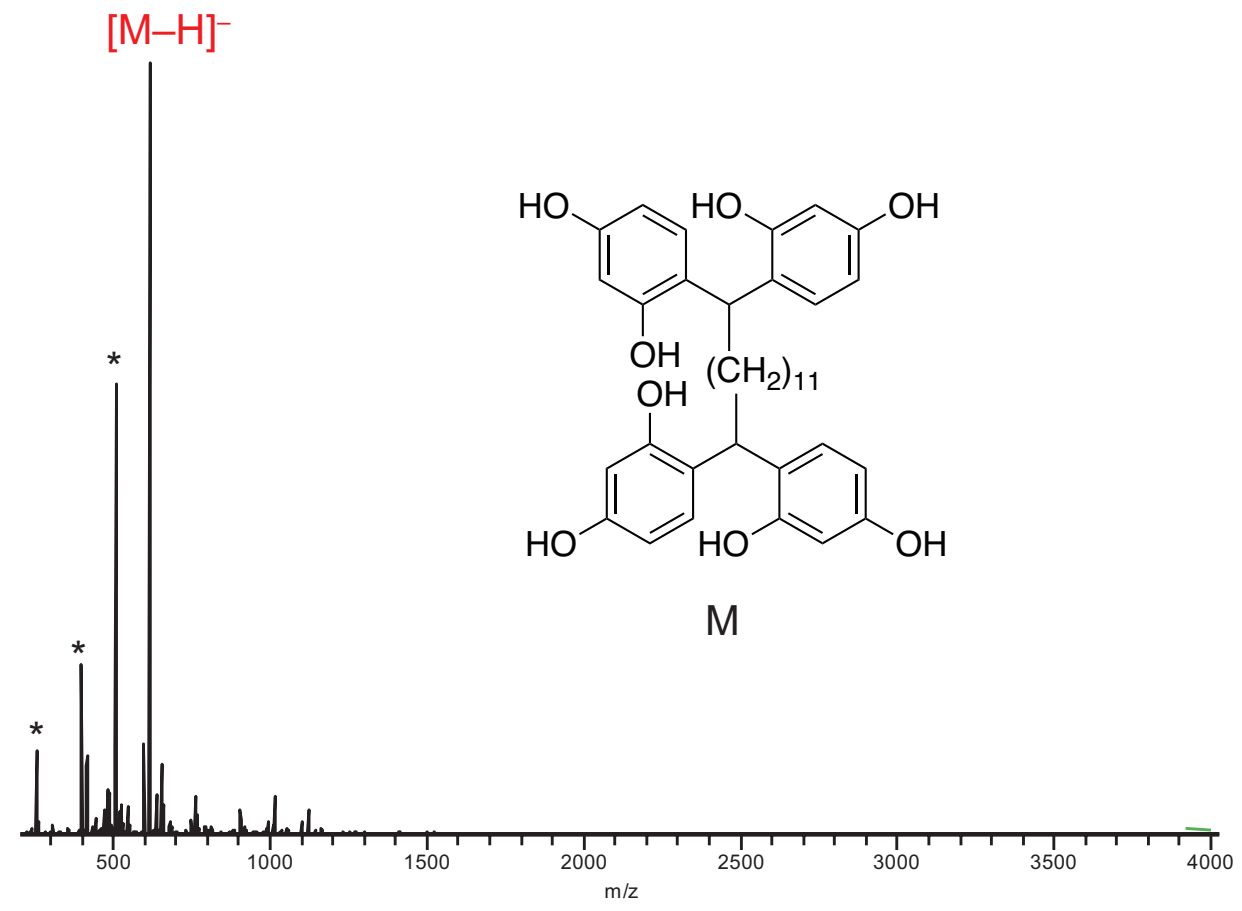

Figure S10. ESI-Orbitrap-MS full spectra of the precipitates in condensation between resorcinol and 1,11-di(1,3-dioxolan-2-yl)undecane. * undefined contamination.

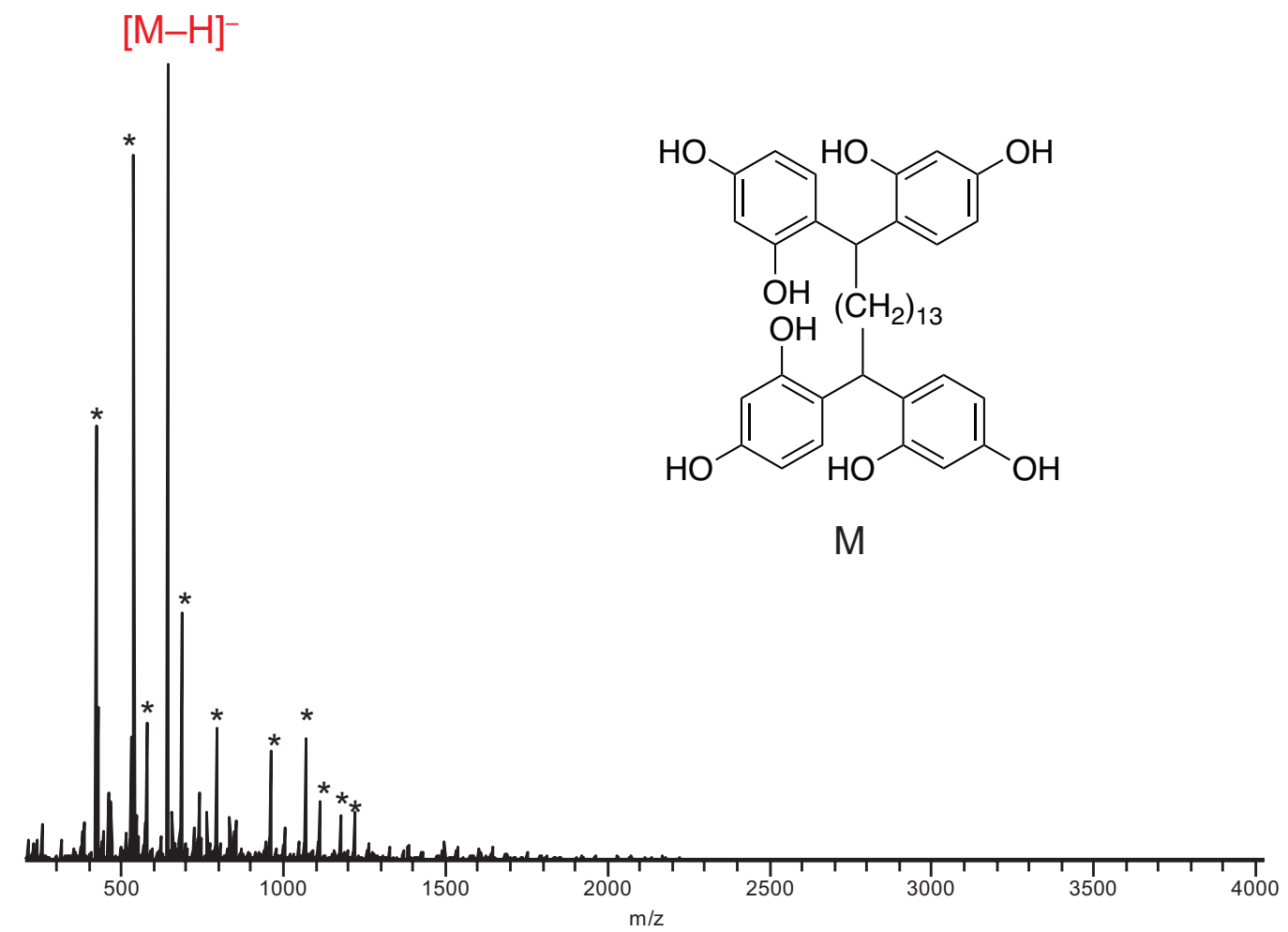

Figure S11. ESI-Orbitrap-MS full spectra of the precipitates in condensation between resorcinol and 1,13-di(1,3-dioxolan-2-yl)tridecane. * undefined contamination. 


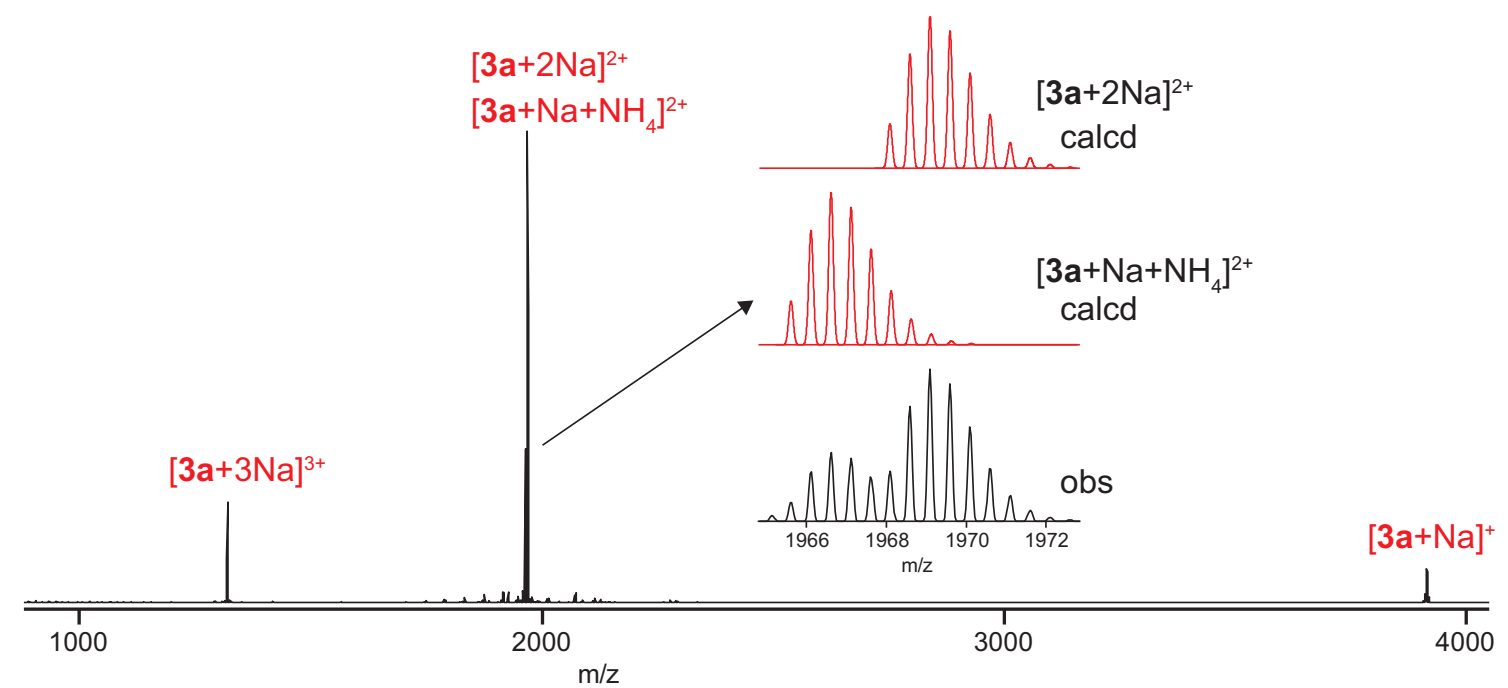

Figure S12. ESI-Orbitrap-MS full spectra of 3a.

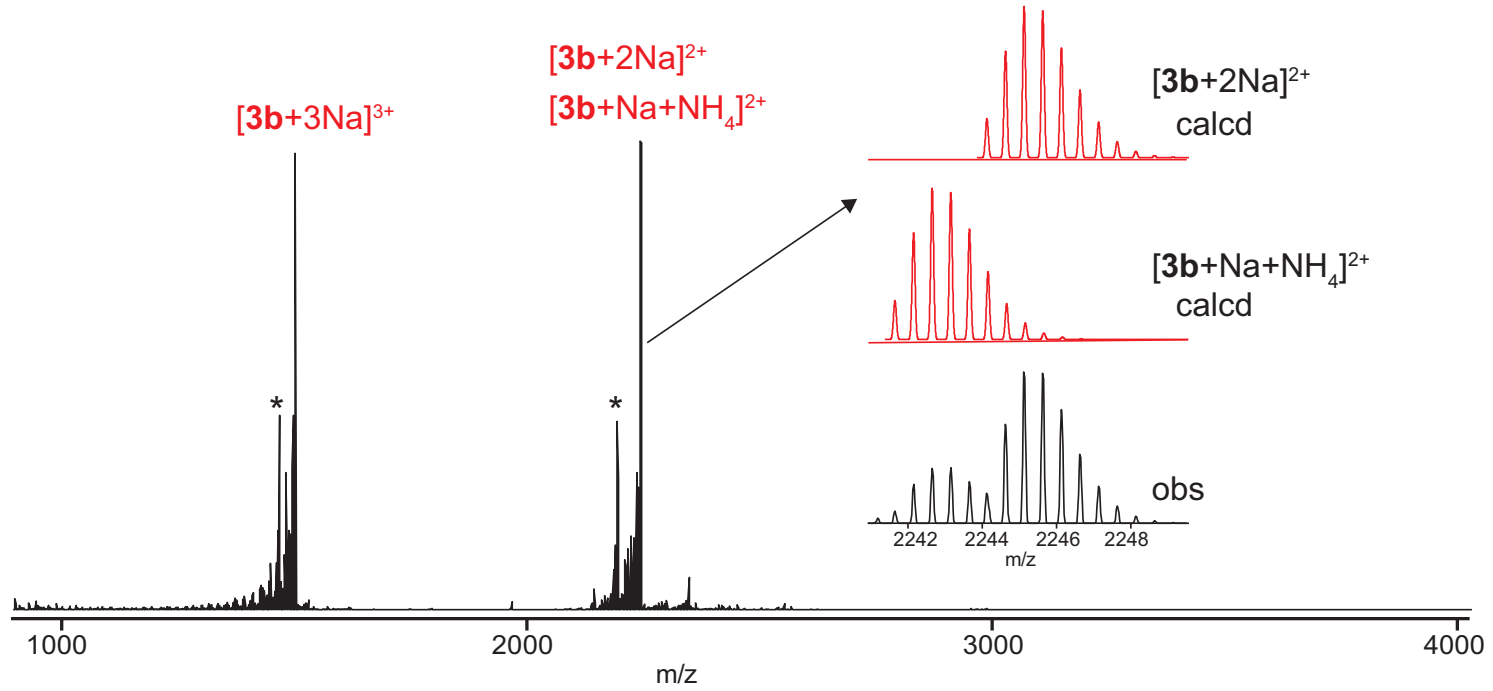

Figure S13. ESI-Orbitrap-MS full spectra of $\mathbf{3 b}$. * undefined contamination. 


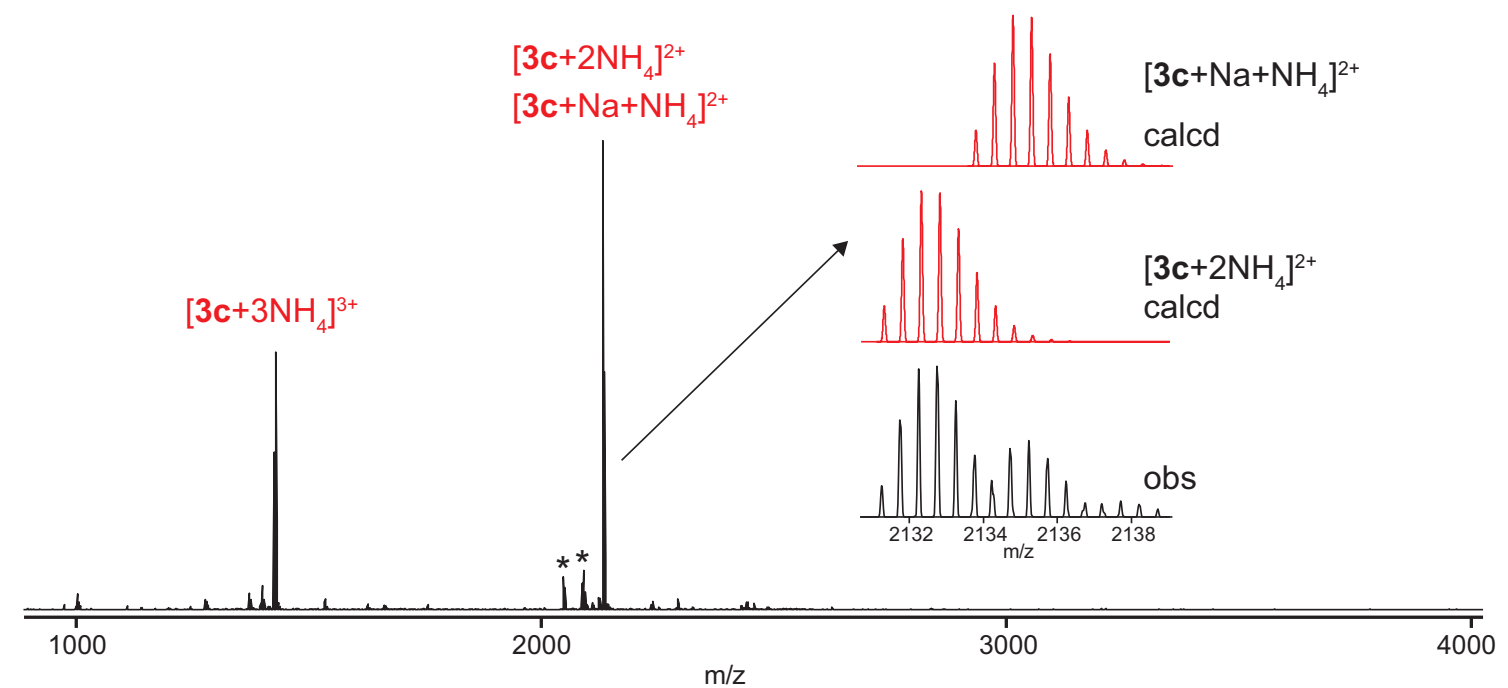

Figure S14. ESI-Orbitrap-MS full spectra of 3c. * undefined contamination. 


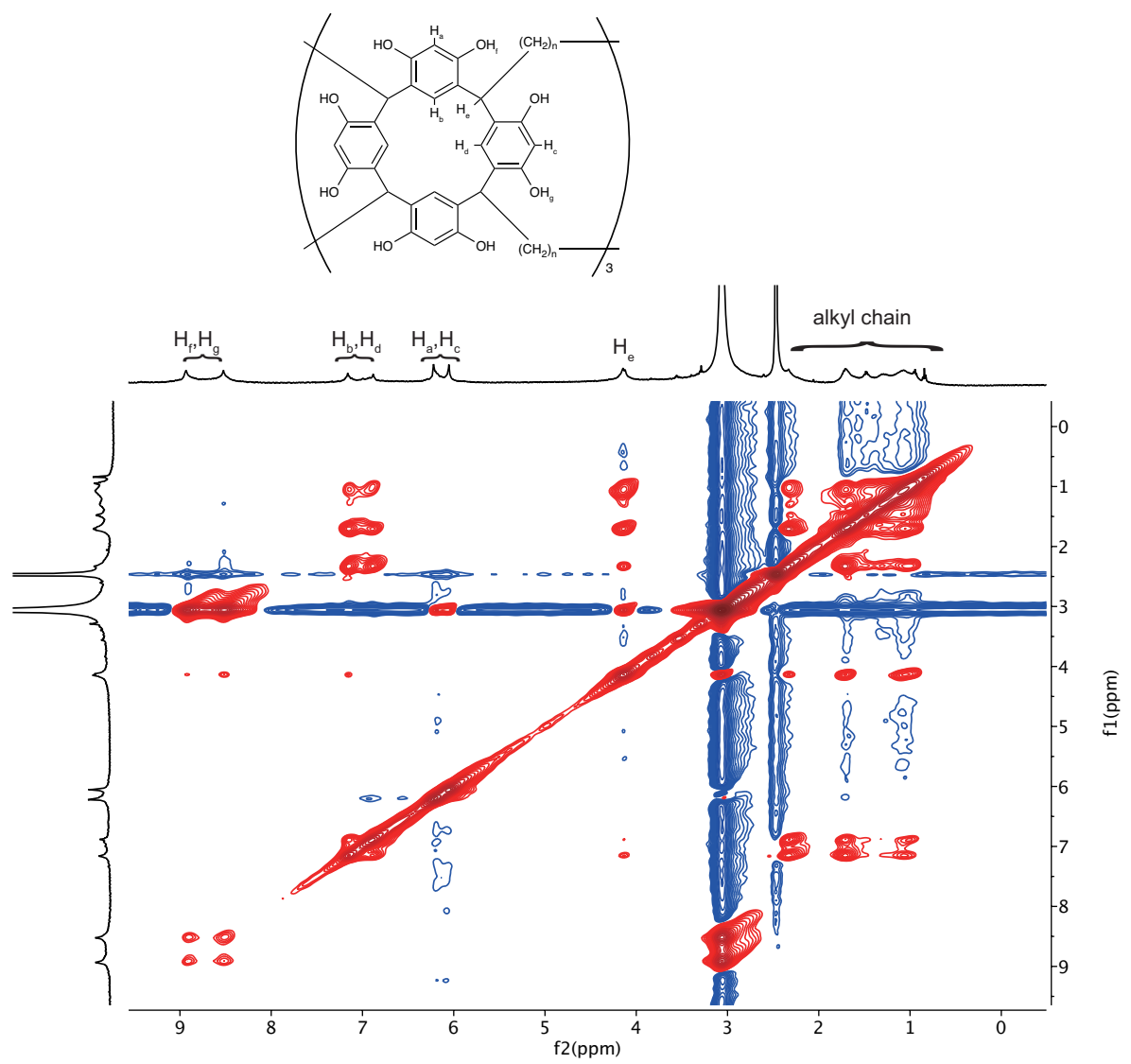

Figure S15. 2D NOESY spectrum $\left(500 \mathrm{MHz}, 80^{\circ} \mathrm{C}\right)$ of $1 \mathrm{a}$ in dimethylsulfoxide- $d_{6}$.

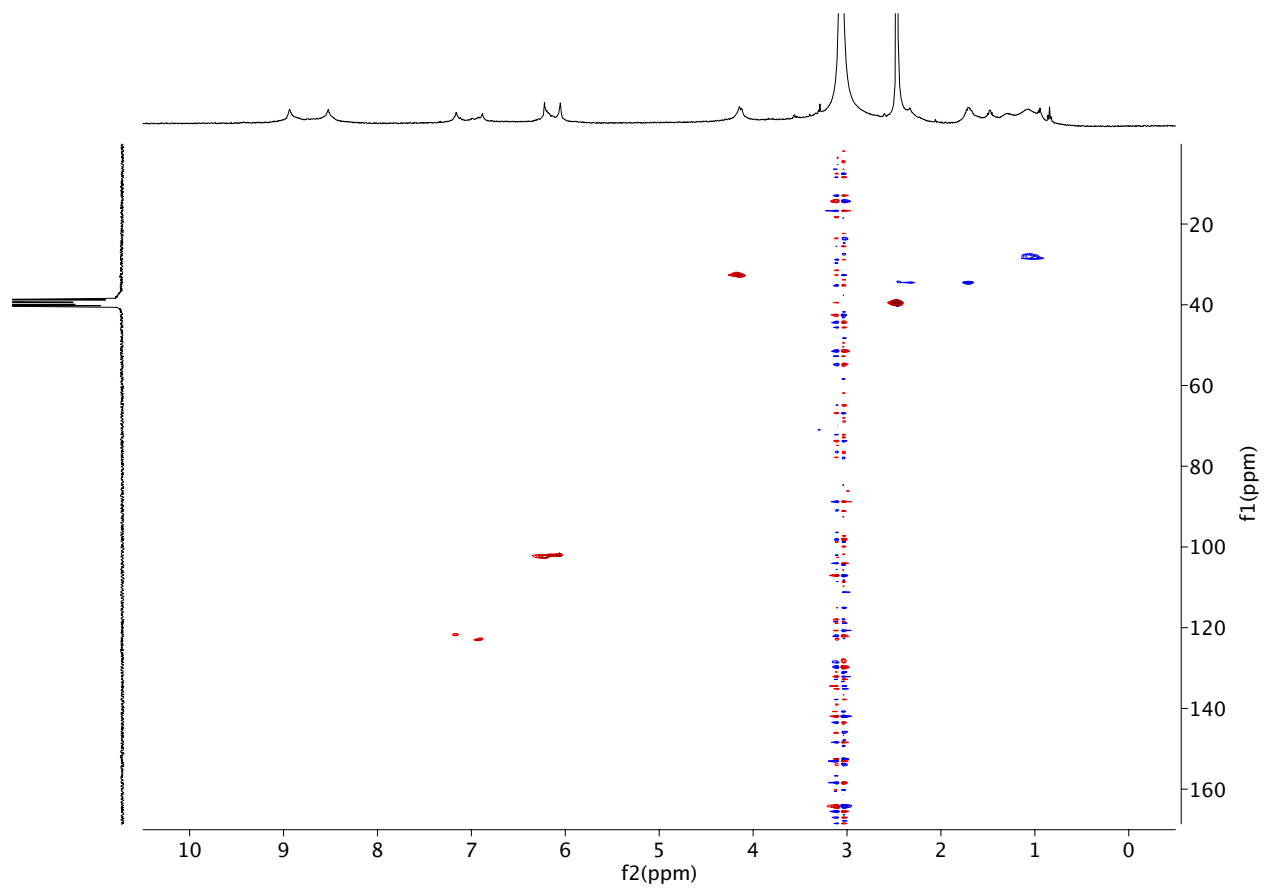

Figure S16. 2D HSQC spectrum $\left(500 \mathrm{MHz}, 80^{\circ} \mathrm{C}\right)$ of $1 \mathbf{a}$ in dimethylsulfoxide- $d_{6}$. 


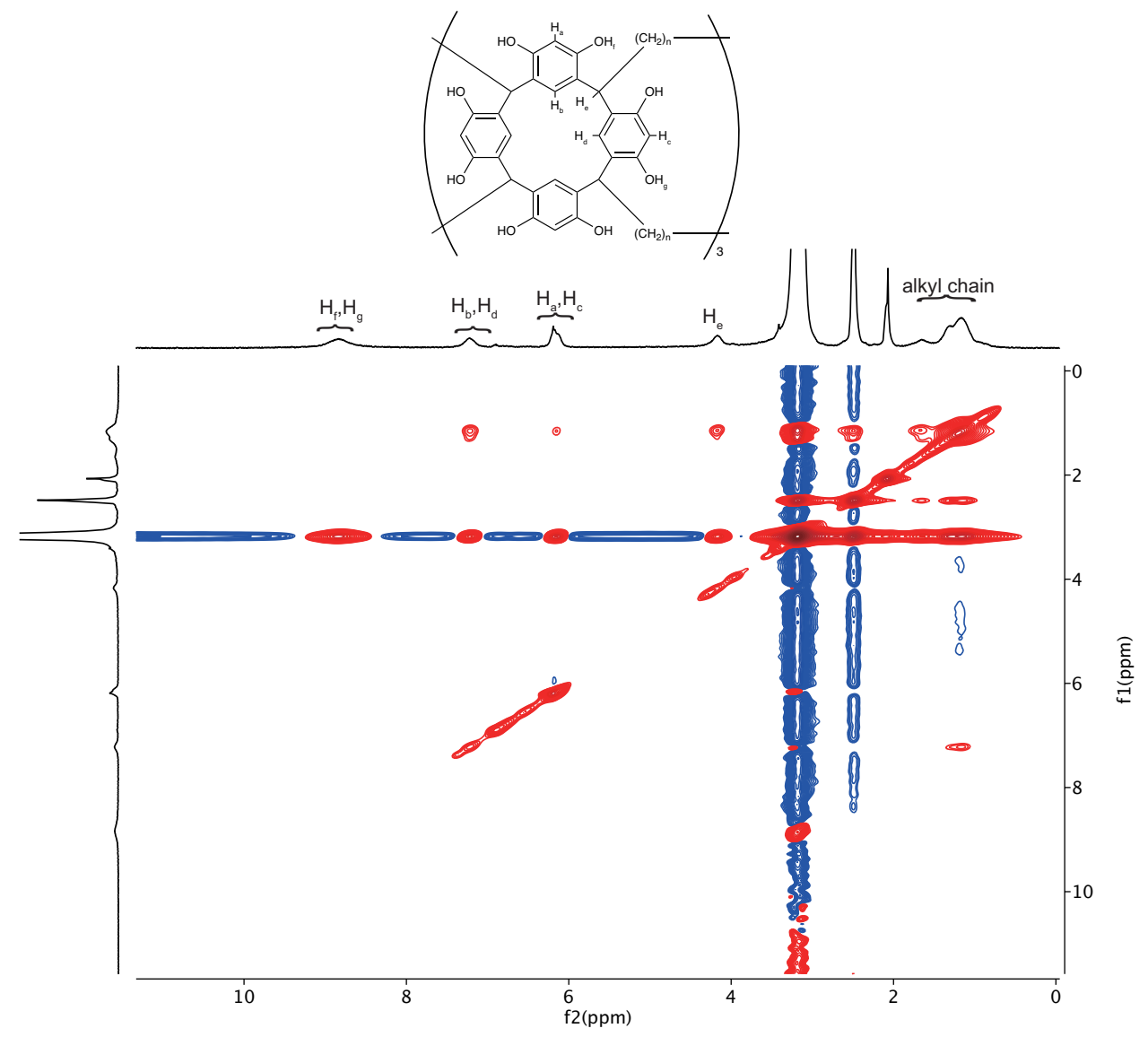

Figure S17. 2D NOESY spectrum $\left(500 \mathrm{MHz}, 80^{\circ} \mathrm{C}\right)$ of $\mathbf{1 b}$ in dimethylsulfoxide- $d_{6}$.

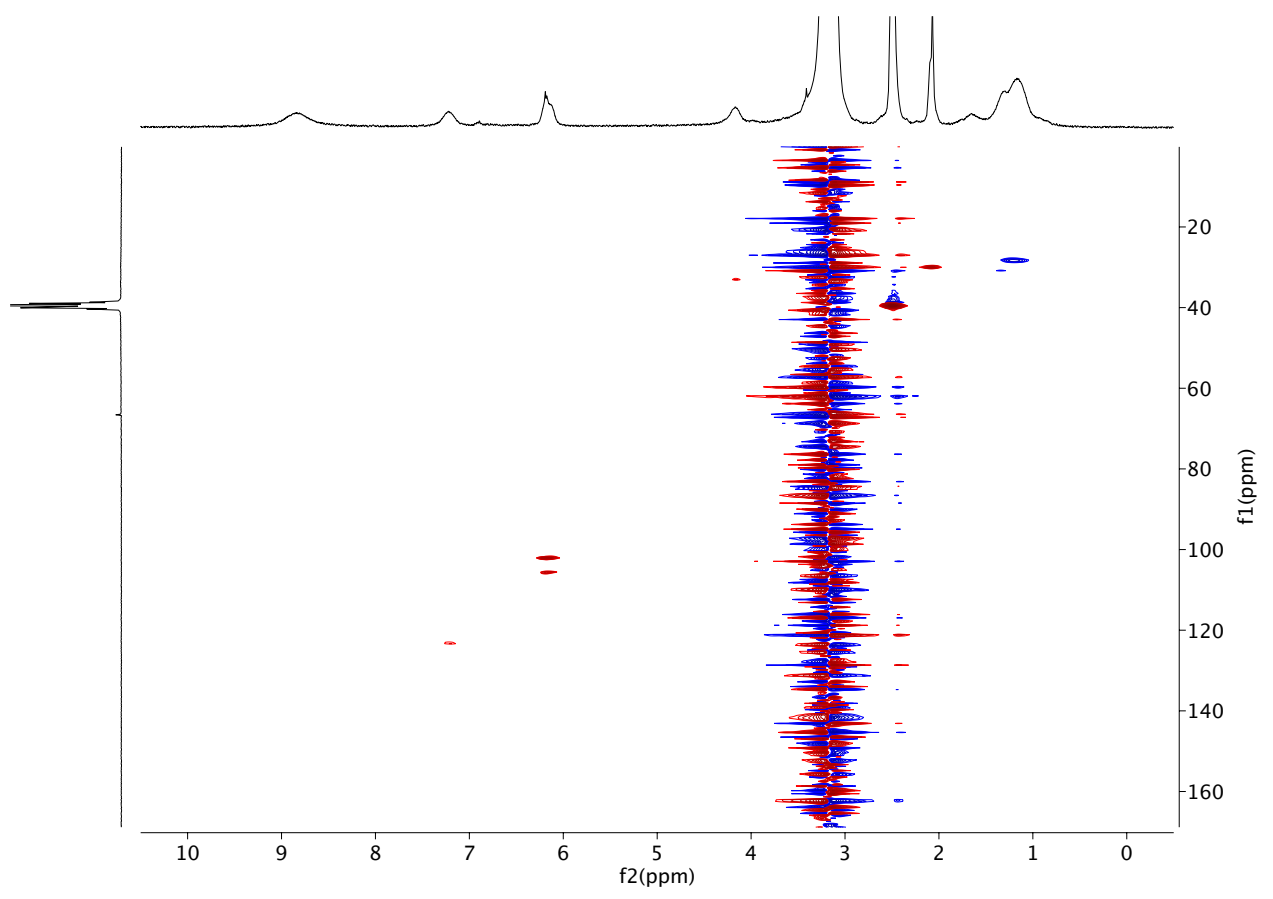

Figure S18. 2D HSQC spectrum $\left(500 \mathrm{MHz}, 80^{\circ} \mathrm{C}\right)$ of $\mathbf{1 b}$ in dimethylsulfoxide- $d_{6}$. 


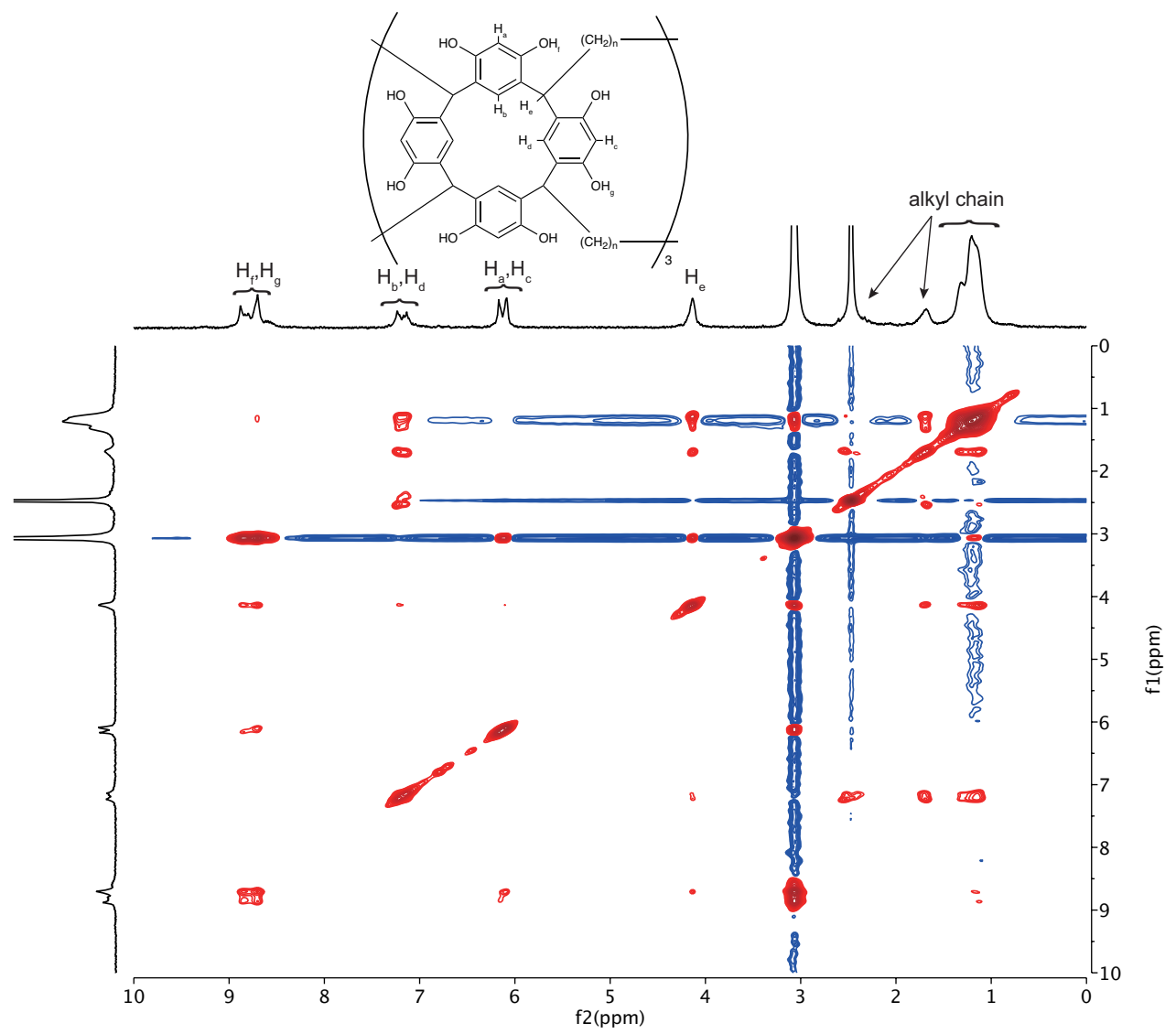

Figure S19. 2D NOESY spectrum $\left(500 \mathrm{MHz}, 80^{\circ} \mathrm{C}\right)$ of $1 \mathrm{c}$ in dimethylsulfoxide- $d_{6}$.

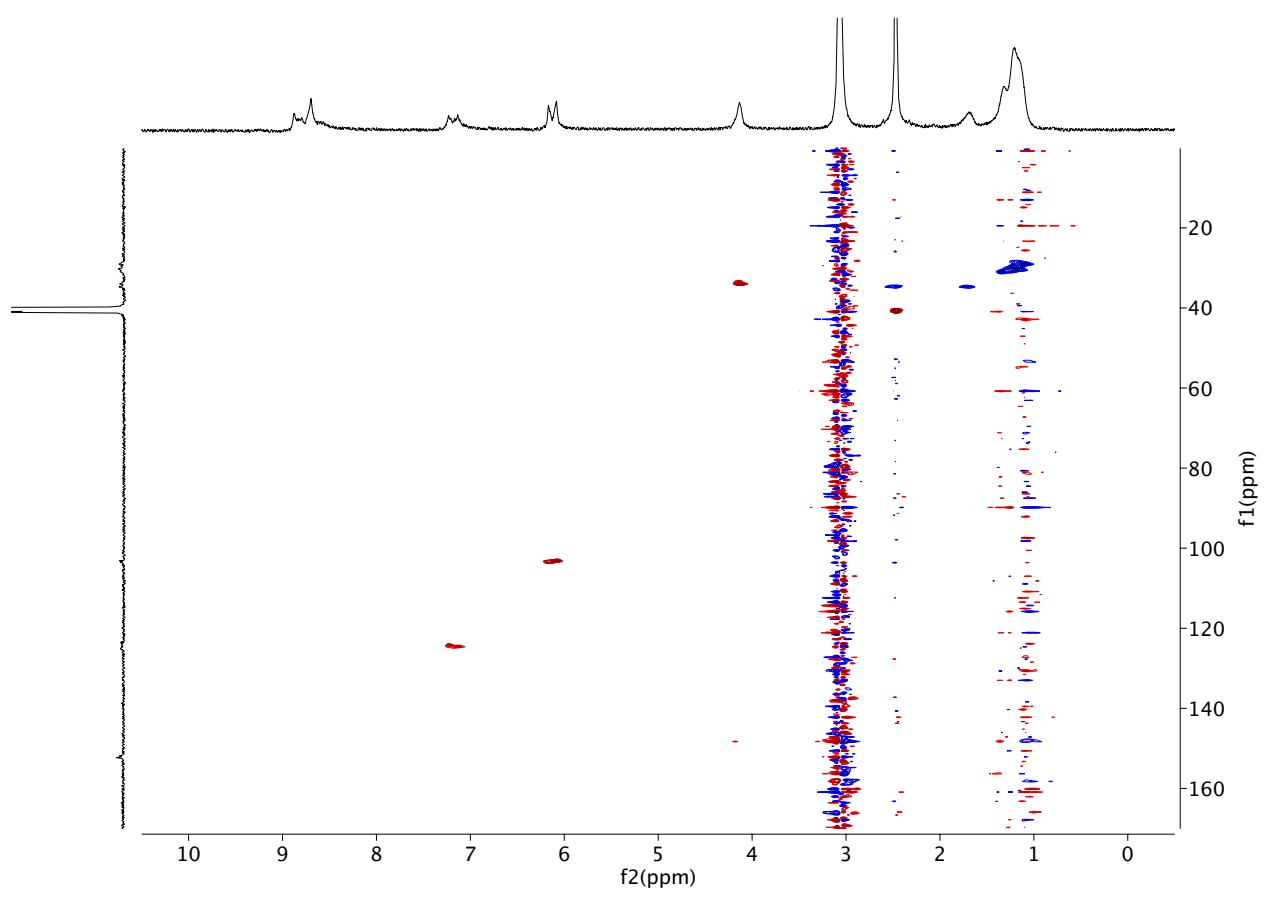

Figure S20. 2D HSQC spectrum $\left(500 \mathrm{MHz}, 80^{\circ} \mathrm{C}\right)$ of $1 \mathbf{c}$ in dimethylsulfoxide- $d_{6}$. 


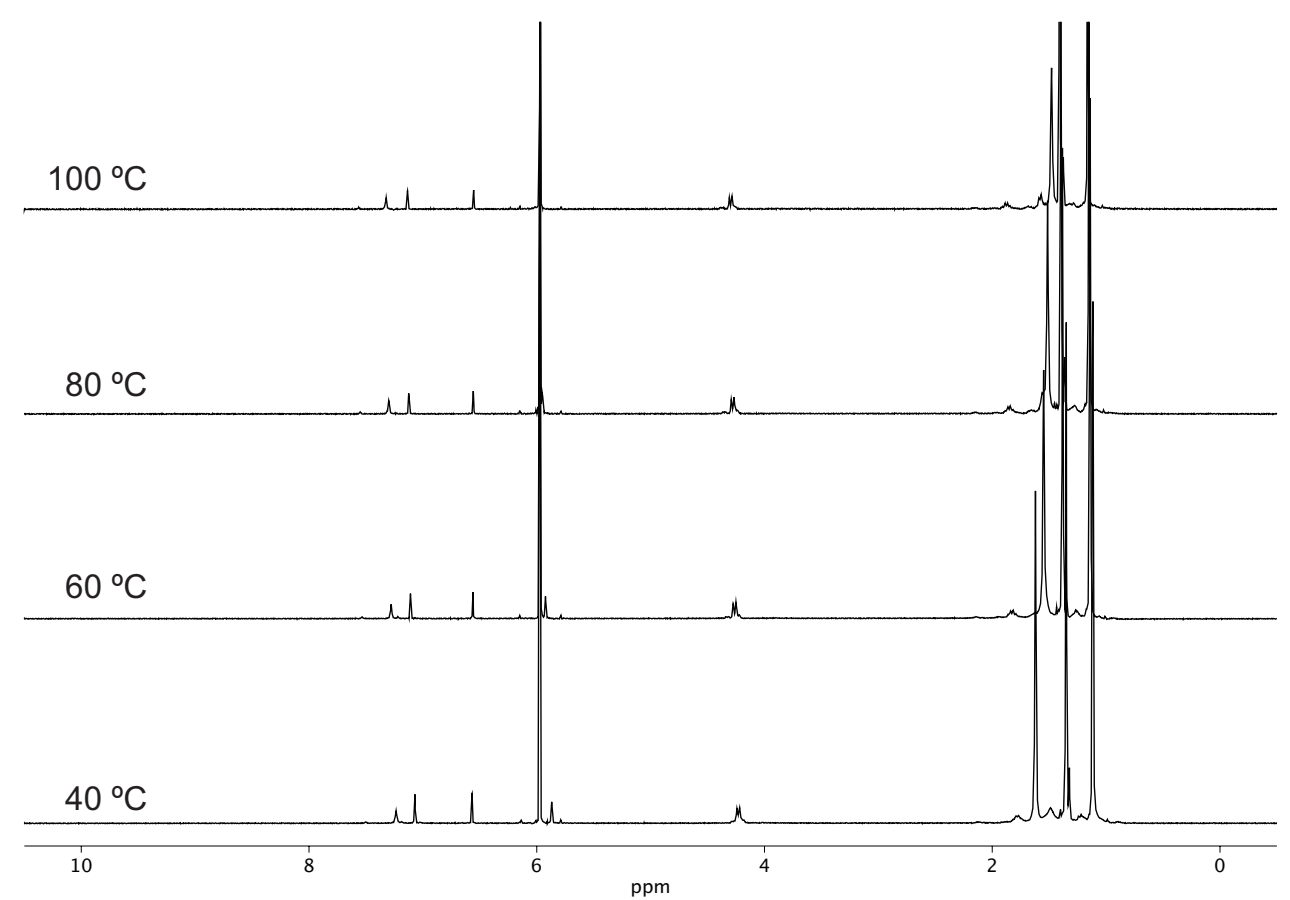

Figure S21. Variable temperature ${ }^{1} \mathrm{H}$ NMR spectra $(500 \mathrm{MHz})$ of 3a in tetrachloroethane- $d_{2}$.

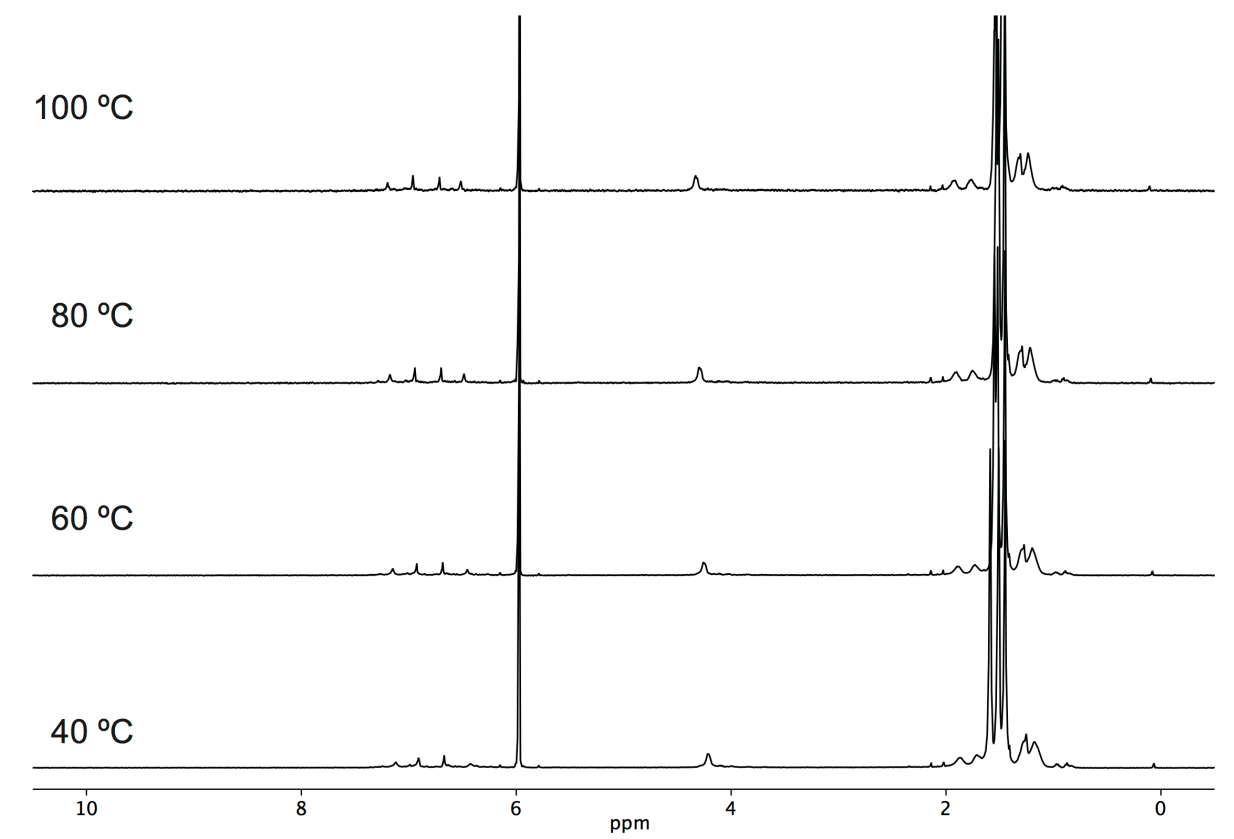

Figure S22. Variable temperature ${ }^{1} \mathrm{H}$ NMR spectra $(500 \mathrm{MHz})$ of $\mathbf{3 b}$ in tetrachloroethane- $d_{2}$. 


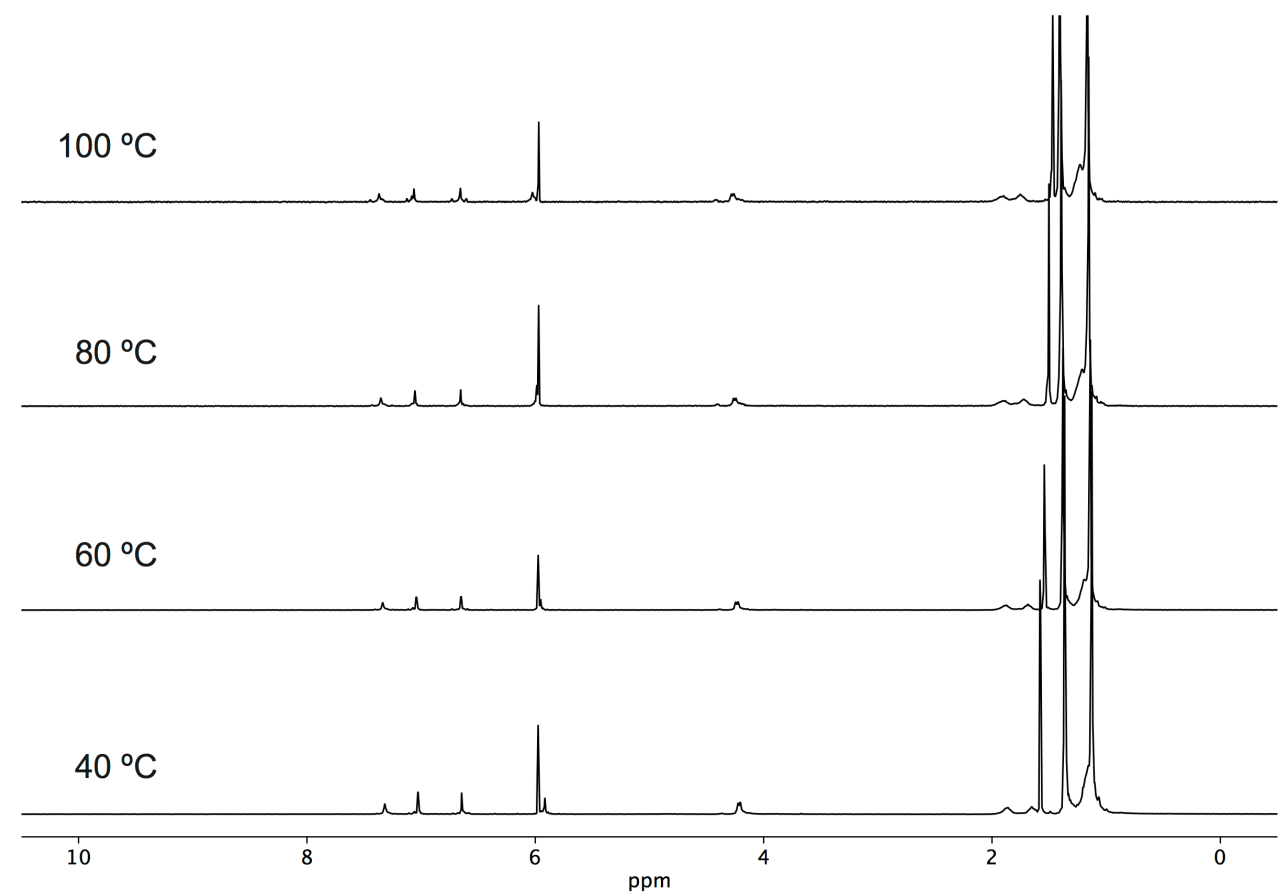

Figure S23. Variable temperature ${ }^{1} \mathrm{H}$ NMR spectra $(500 \mathrm{MHz})$ of $\mathbf{3 c}$ in tetrachloroethane- $d_{2}$.

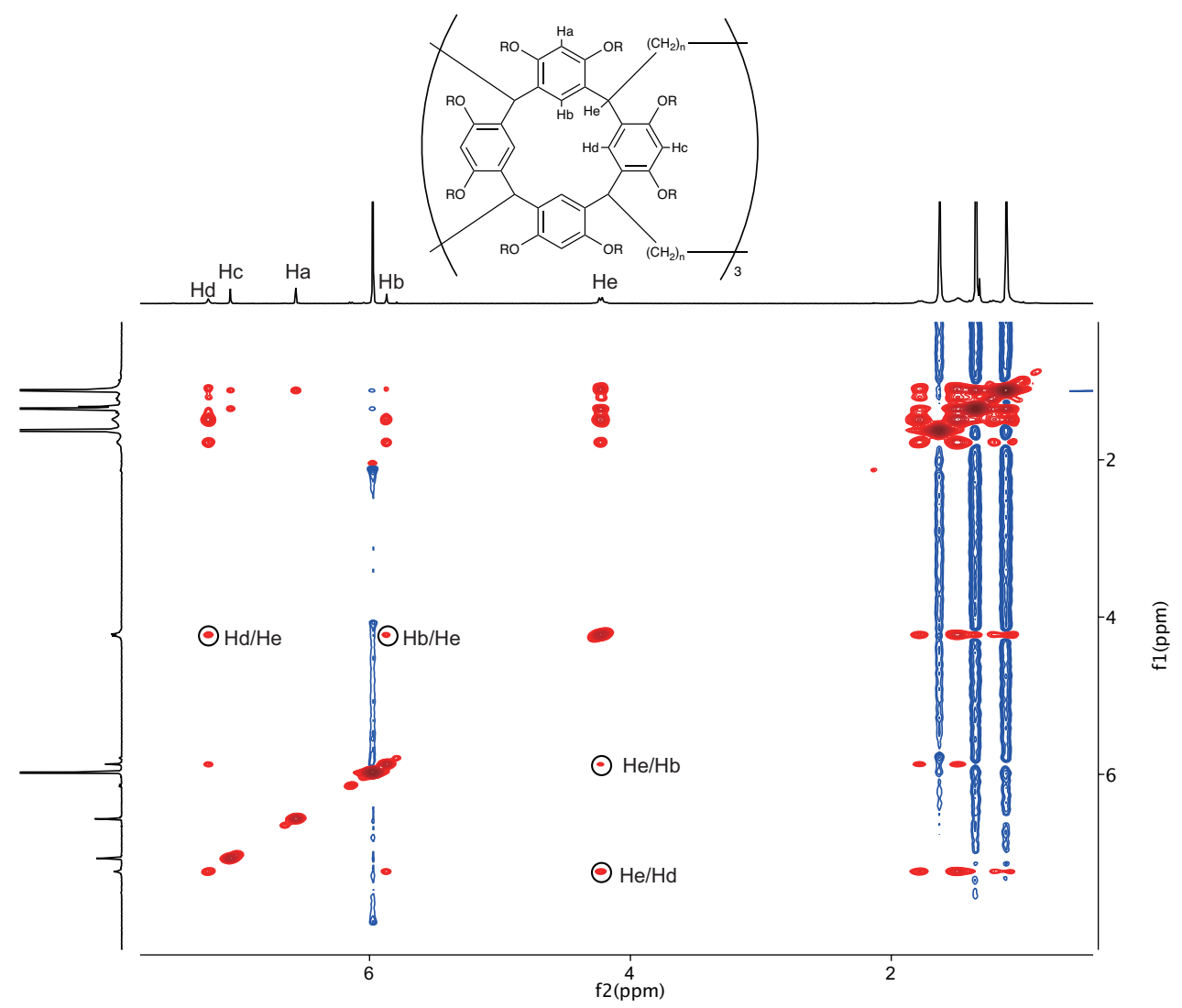

Figure S24. 2D NOESY spectrum (500 MHz) of 3a in tetrachloroethane- $d_{2}$. 


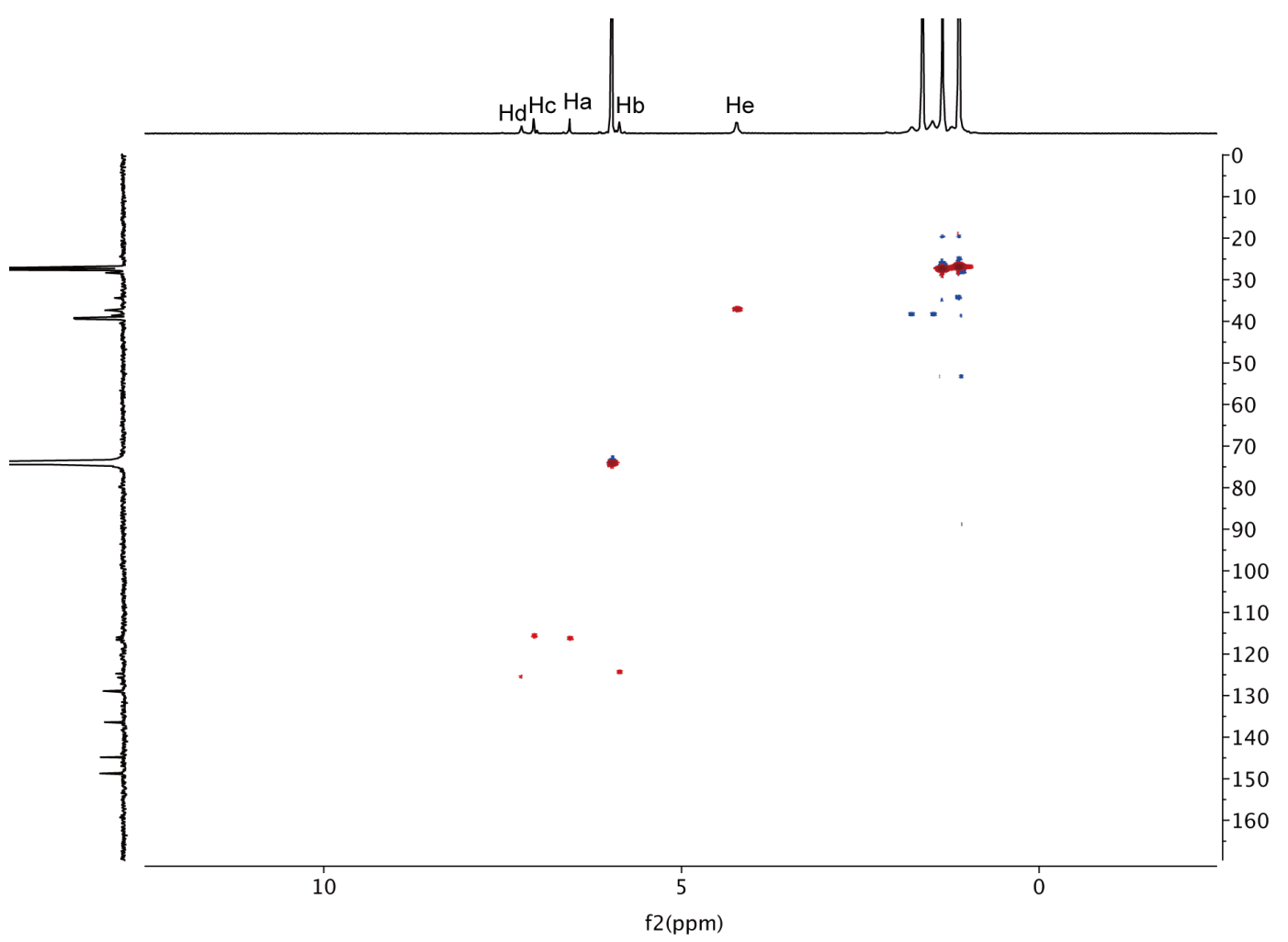

Figure S25. 2D HSQC spectrum (500 MHz) of 3a in tetrachloroethane- $d_{2}$.

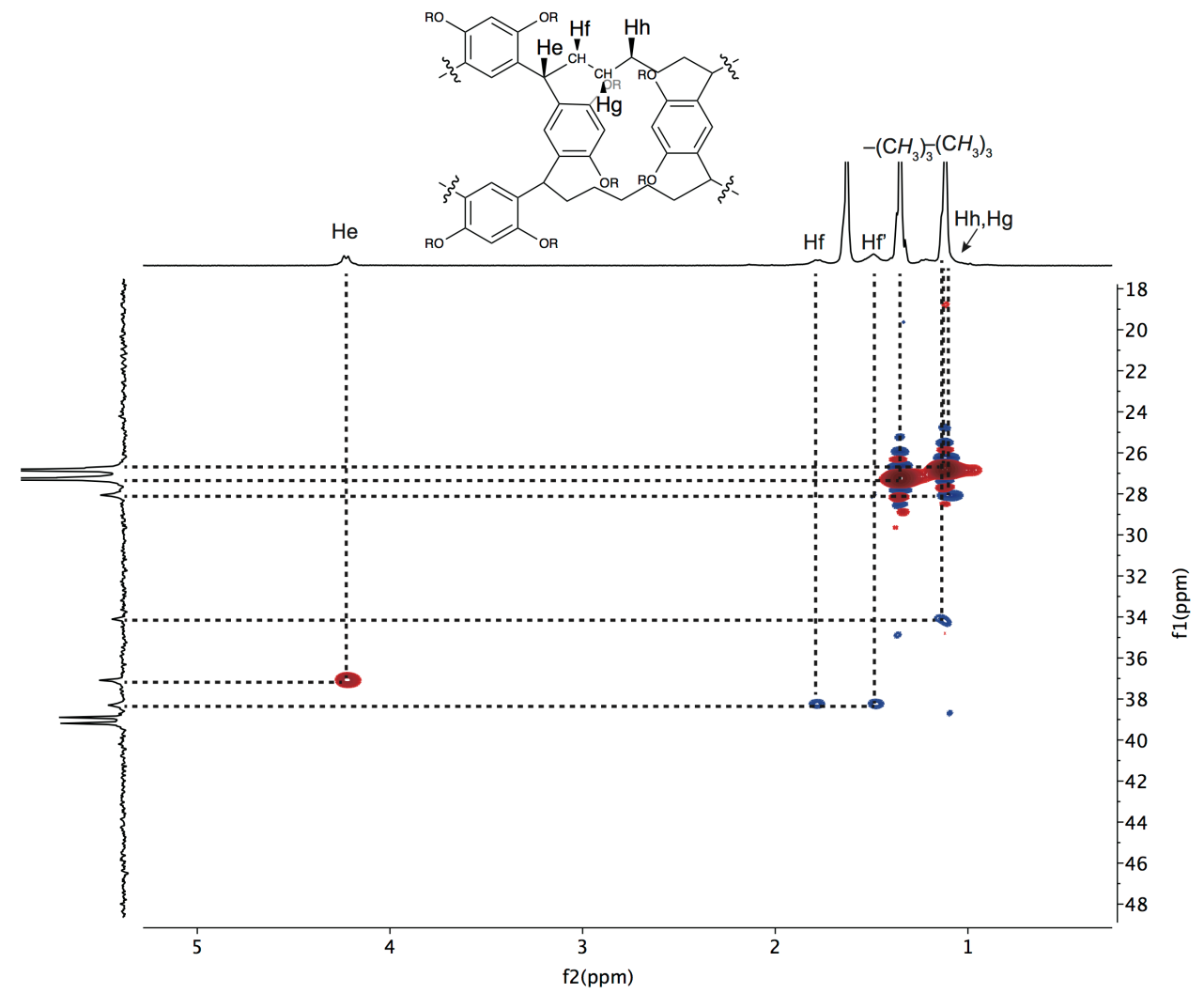

Figure S26. Selected regions of 2D HSQC spectrum (500 MHz) of 3a in tetrachloroethane- $d_{2}$. 


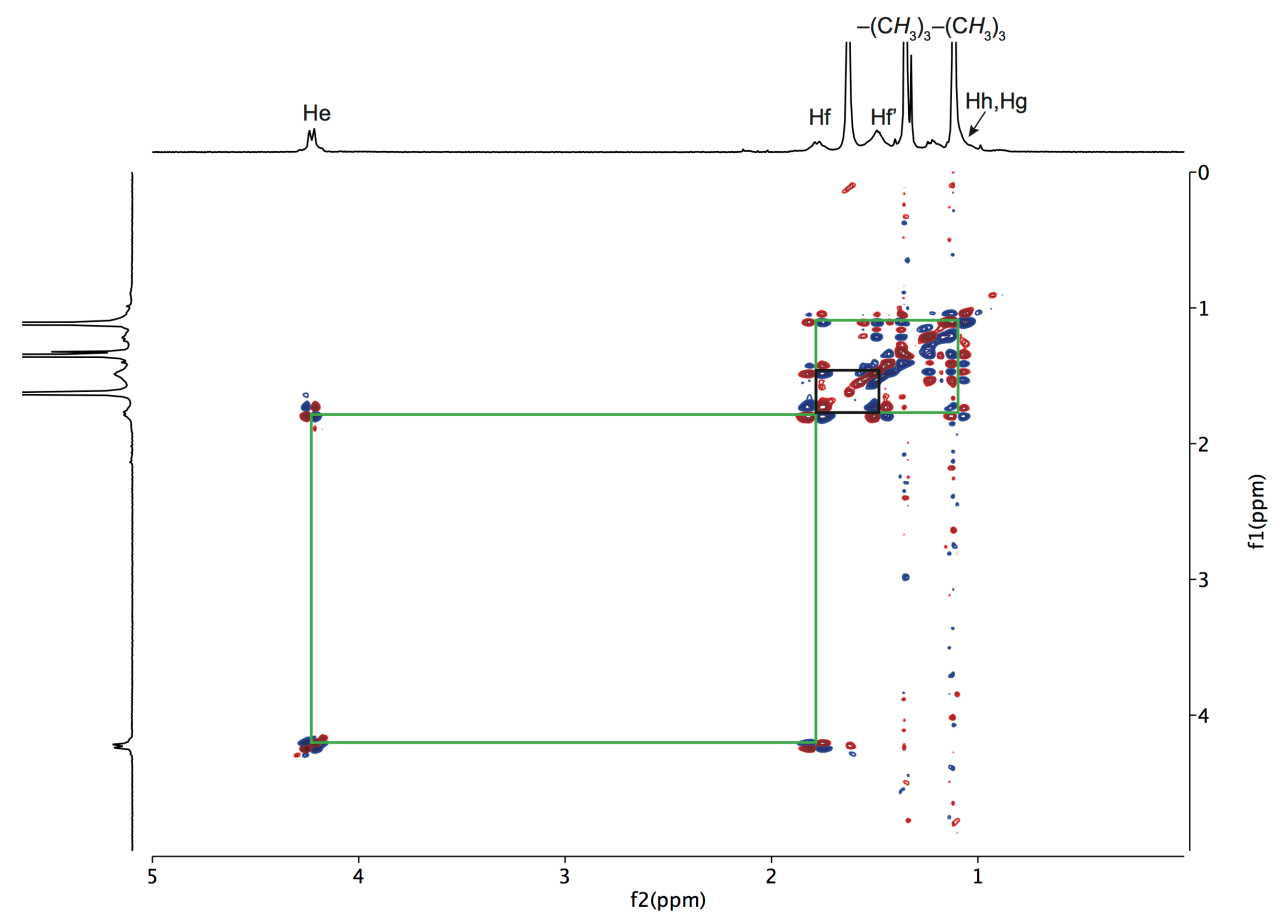

Figure S27. DQF-COSY spectrum (500 MHz) of 3a in tetrachloroethane- $d_{2}$.

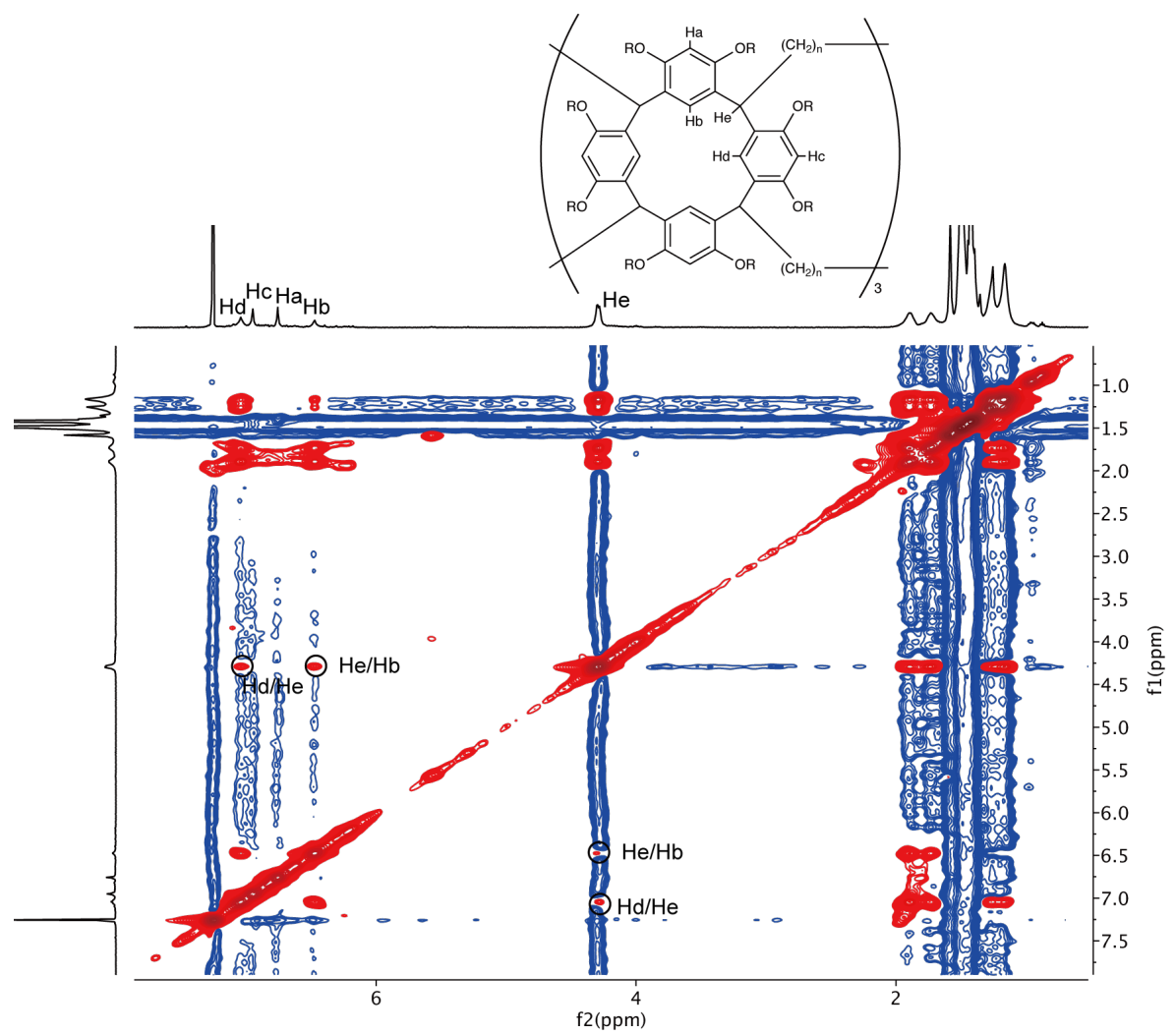

Figure S28. 2D NOESY spectrum (500 MHz) of $\mathbf{3 b}$ in chloroform- $d_{1}$. 


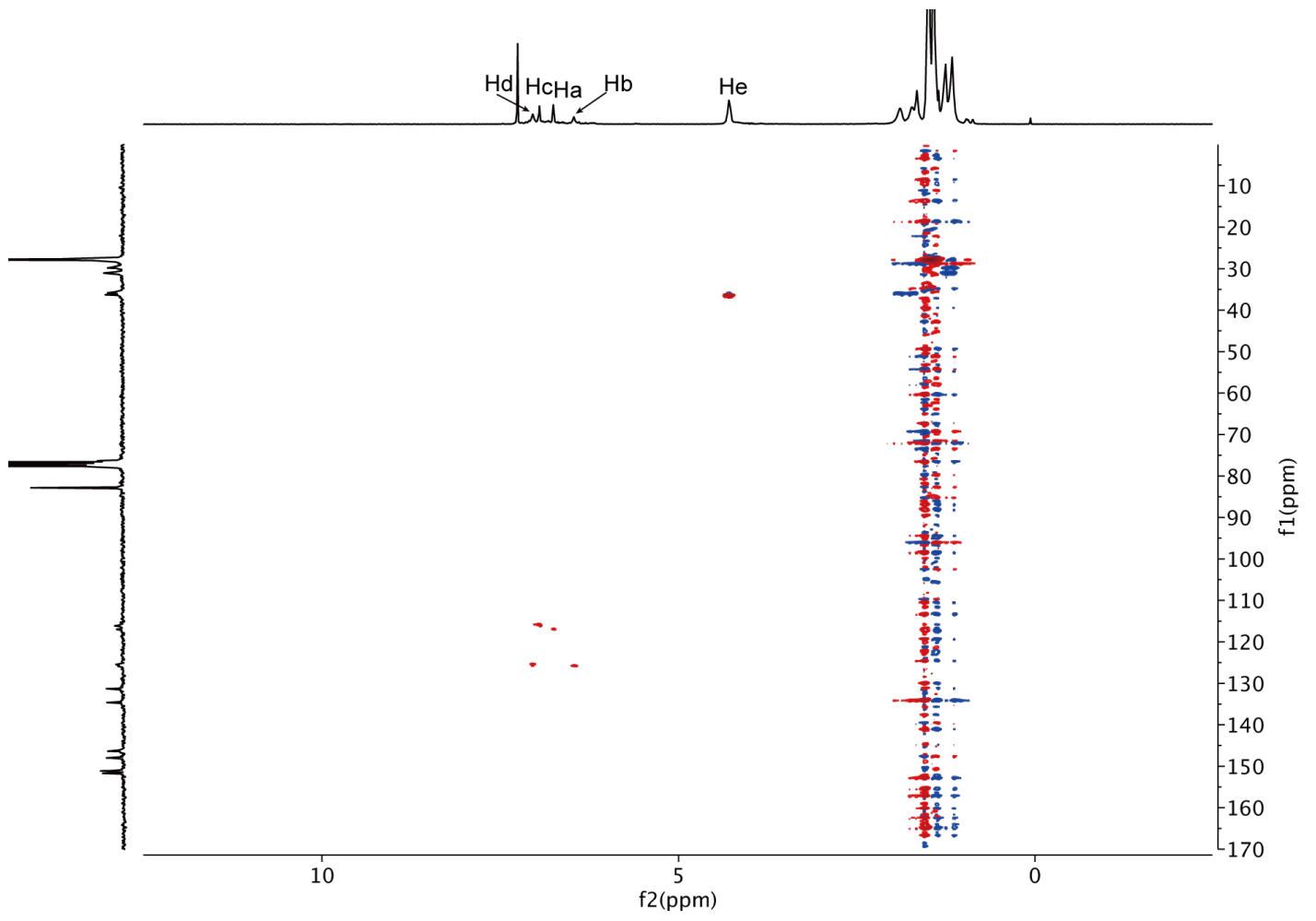

Figure S29. 2D HSQC spectrum (500 MHz) of $\mathbf{3 b}$ in chloroform- $d_{1}$.

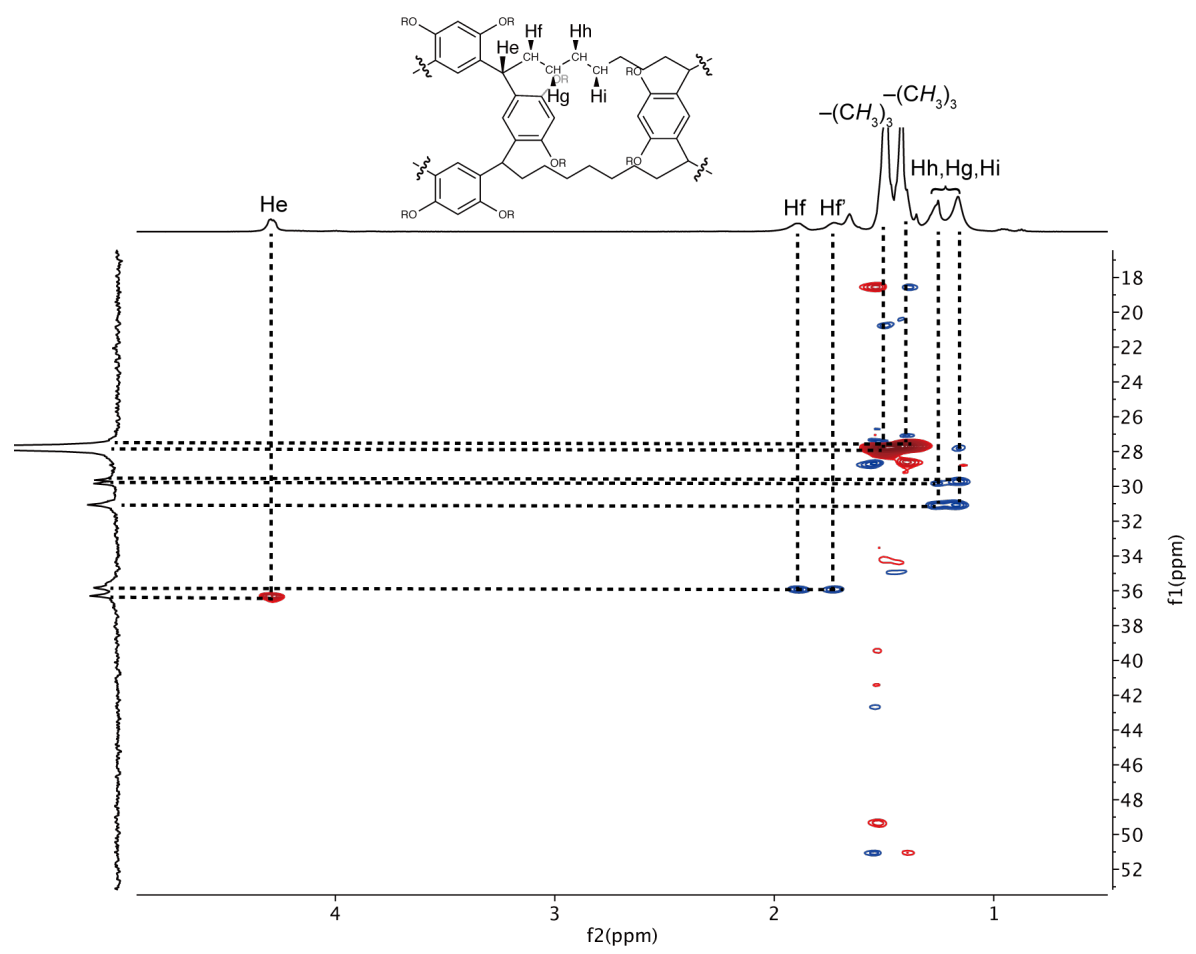

Figure S30. Selected regions of 2D HSQC spectrum (500 MHz) of $\mathbf{3 b}$ in chloroform- $d_{1}$. 


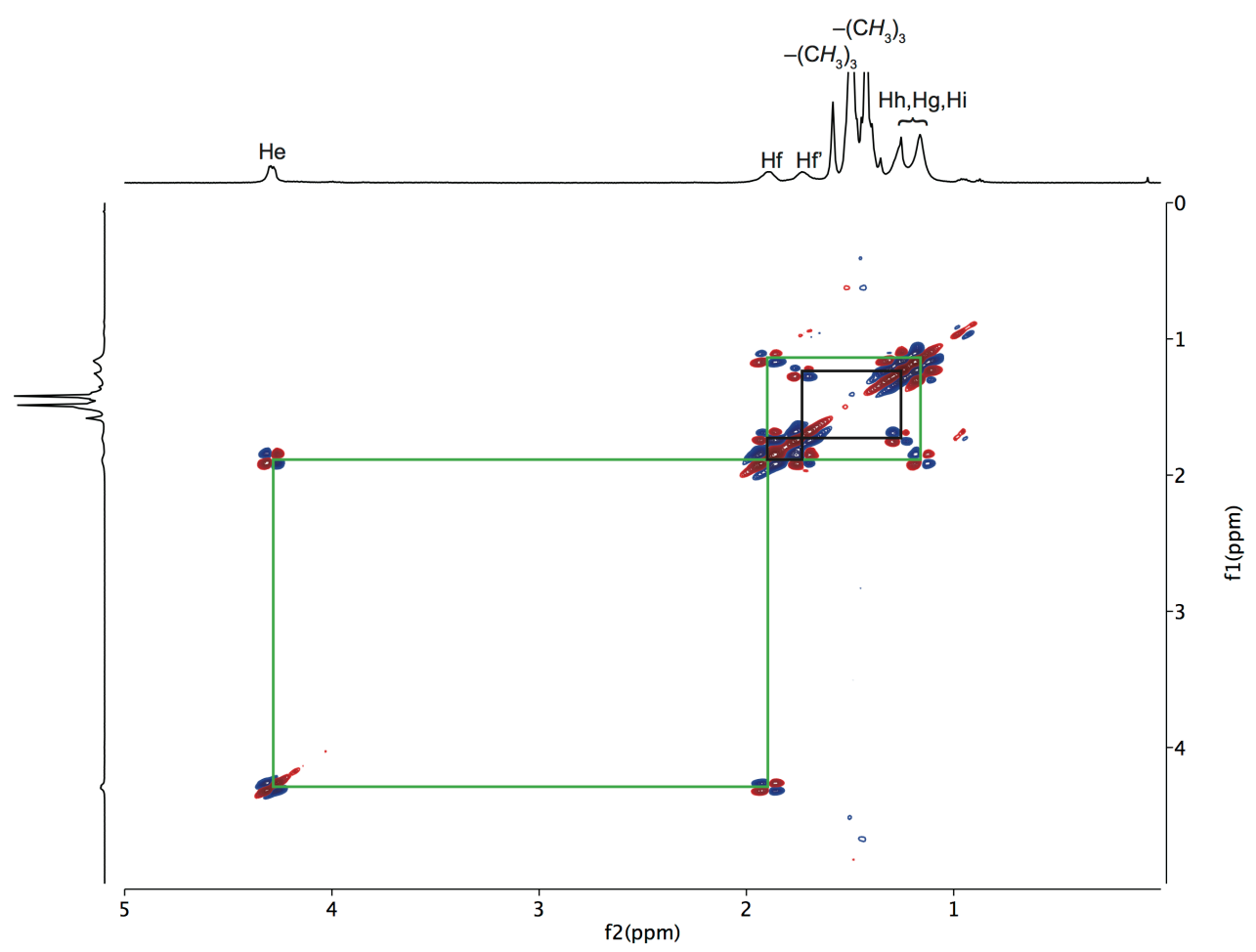

Figure S31. DQF-COSY spectrum (500 MHz) of $3 \mathbf{b}$ in chloroform- $d_{1}$.

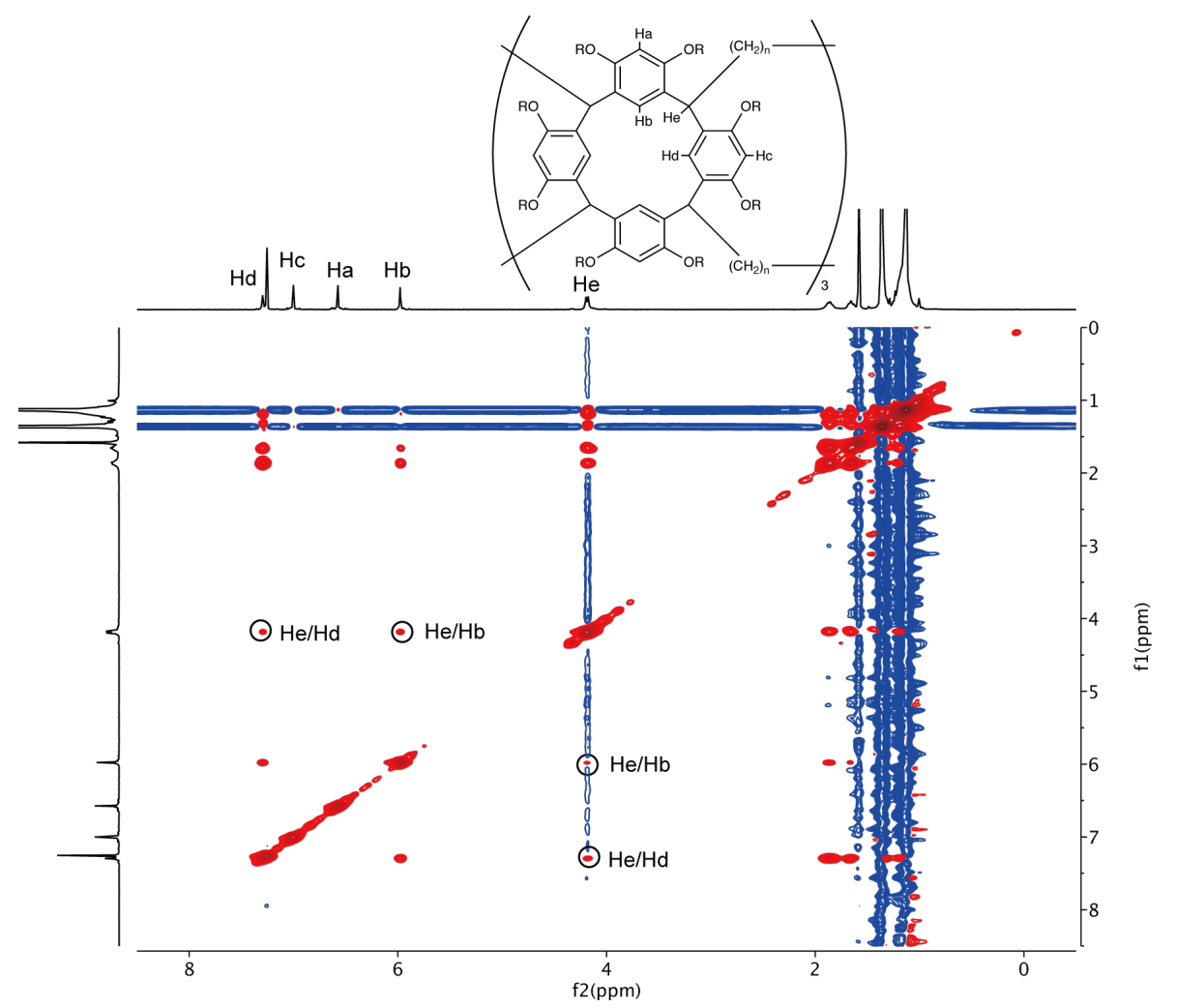

Figure S32. 2D NOESY spectrum $(500 \mathrm{MHz})$ of $\mathbf{3 c}$ in chloroform- $d_{1}$. 


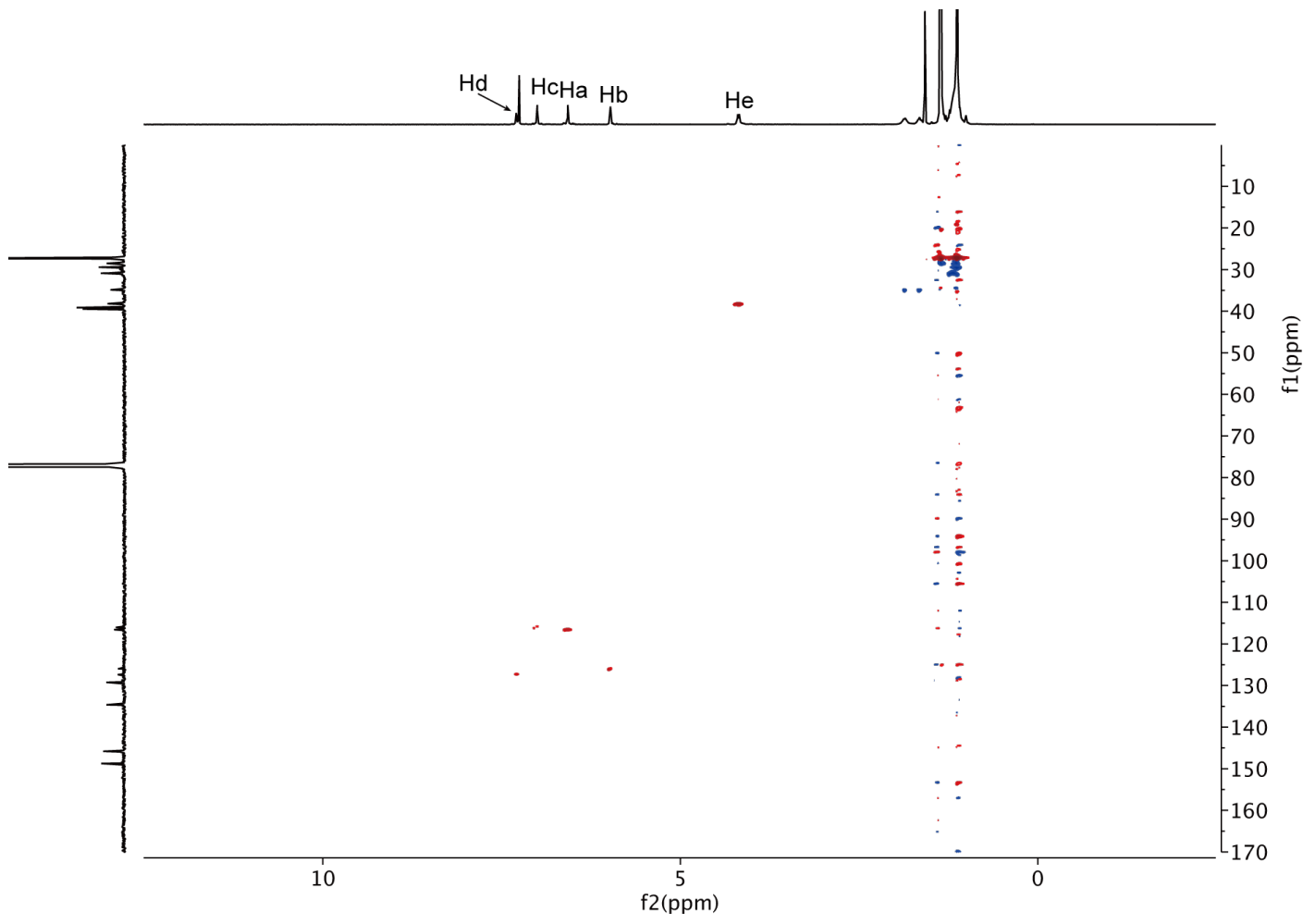

Figure S33. 2D HSQC spectrum (500 MHz) of 3c in chloroform- $d_{1}$.

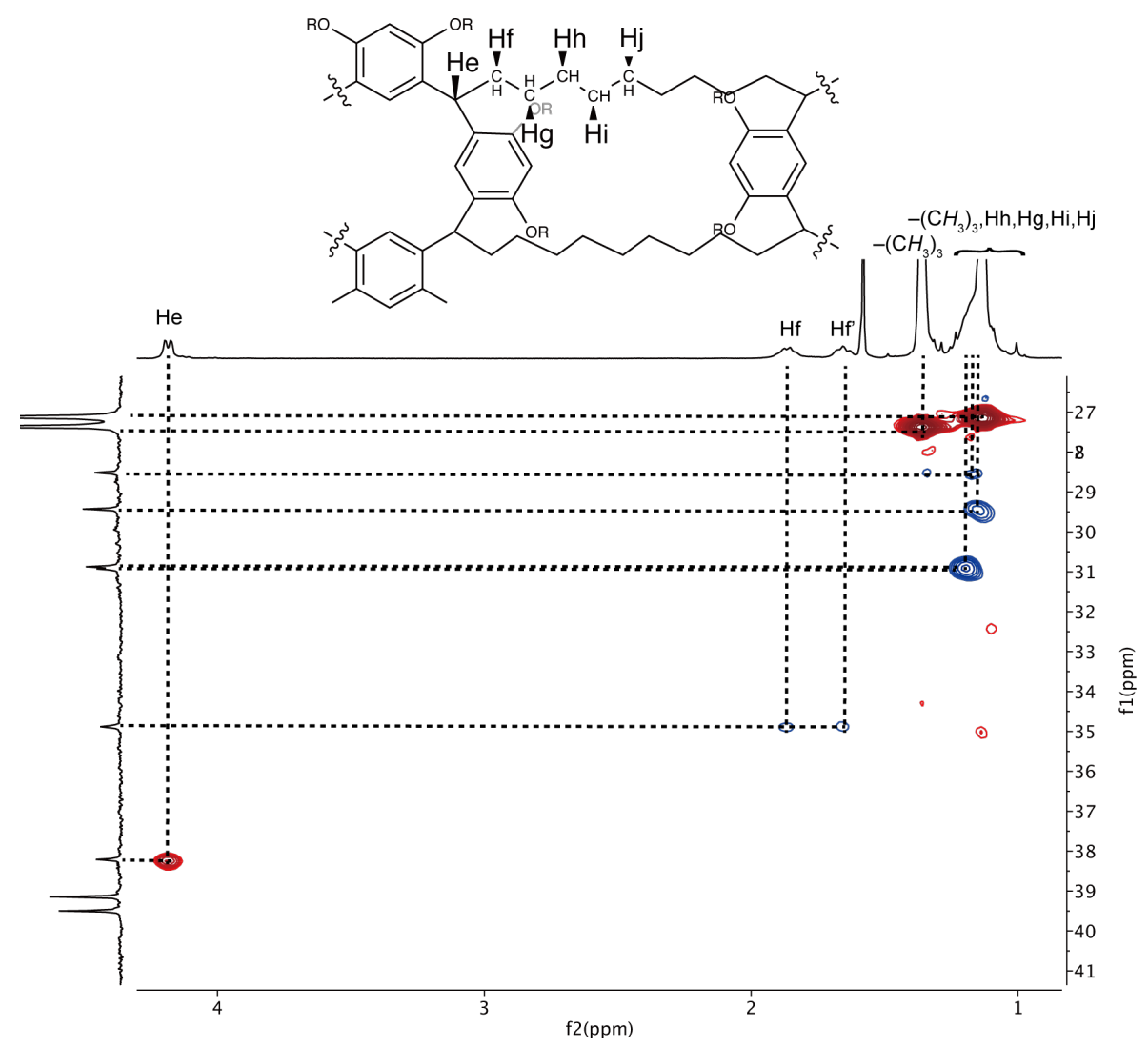

Figure S34. Selected regions of 2D HSQC spectrum (500 MHz) of $3 \mathbf{c}$ in chloroform- $d_{1}$. 


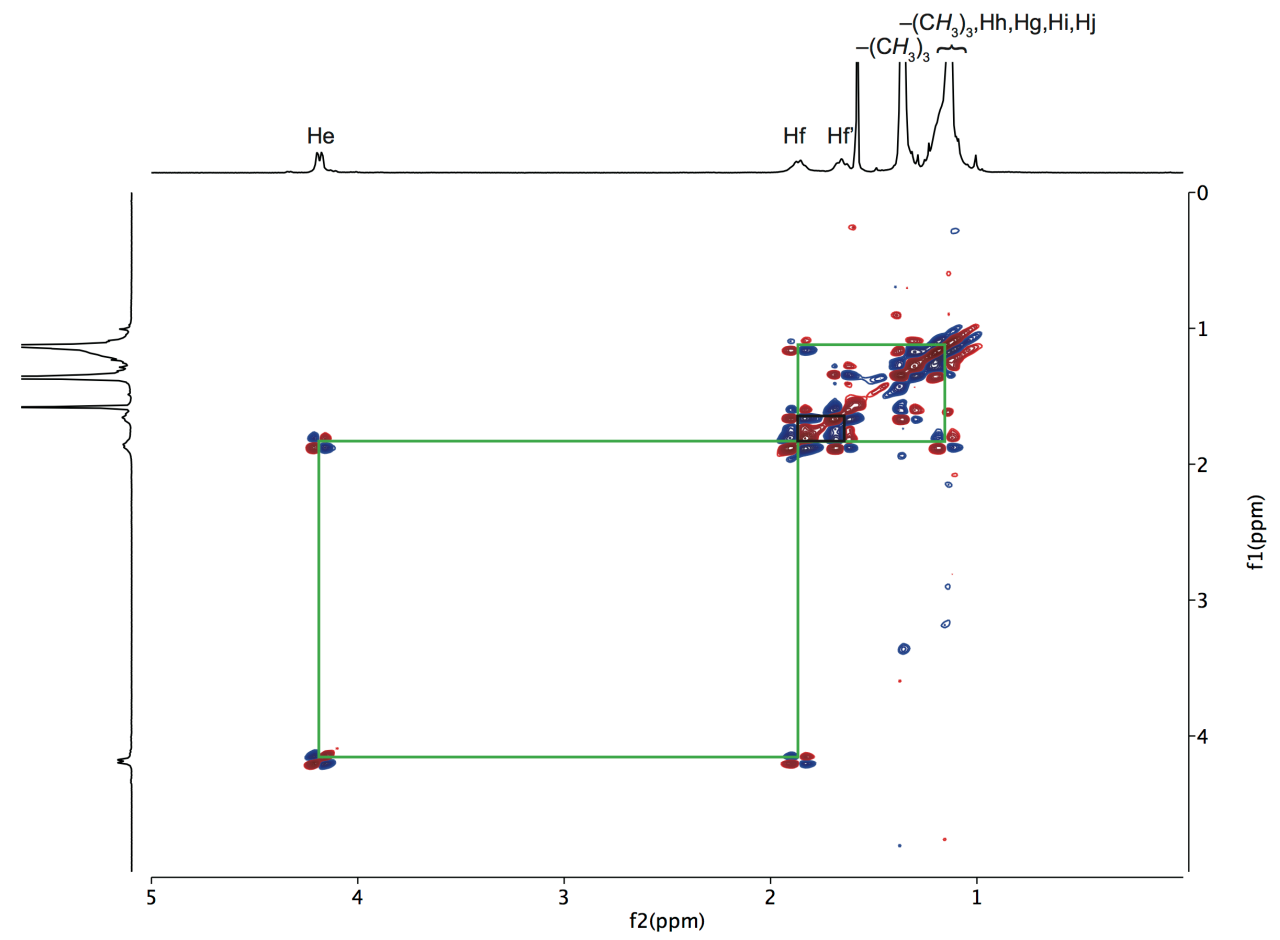

Figure S35. DQF-COSY spectrum (500 MHz) of $3 \mathbf{c}$ in chloroform- $d_{1}$. 
Table S1. Crystallographic parameters of 3a-c.

\begin{tabular}{|c|c|c|c|}
\hline Crystal & $\mathbf{3 a}$ & $\mathbf{3 b}$ & $3 c$ \\
\hline Formula & $\mathrm{C}_{252} \mathrm{H}_{330} \mathrm{O}_{48}$ & $\mathrm{C}_{230} \mathrm{H}_{278} \mathrm{O}_{68}$ & $\mathrm{C}_{233} \mathrm{H}_{307} \mathrm{O}_{43}$ \\
\hline Formula weight & 4127.18 & 4130.54 & 3795.81 \\
\hline Crystal system & monoclinic & monoclinic & monoclinic \\
\hline Space group & $P 2_{1} / c$ & $P 2_{1} / c$ & $P 2_{1} / c$ \\
\hline a/ $\AA$ & $24.728(4)$ & $41.967(4)$ & $26.825(6)$ \\
\hline$b / \AA$ & $26.159(4)$ & $18.1163(17)$ & $23.291(5)$ \\
\hline$c / \AA$ & $44.219(7)$ & $41.002(4)$ & $48.994(11)$ \\
\hline$\alpha /^{\circ}$ & 90 & 90 & 90 \\
\hline$\beta /^{\circ}$ & $92.536(2)$ & $94.532(3)$ & $91.078(3)$ \\
\hline$\gamma^{\circ}$ & 90 & 90 & 90 \\
\hline$V / \AA^{3}$ & $28576(8)$ & $31076(5)$ & $30605(12)$ \\
\hline$d_{\text {calc. }} / \mathrm{g} \mathrm{cm}^{-3}$ & 0.959 & 0.883 & 0.824 \\
\hline$Z$ & 4 & 4 & 4 \\
\hline $2 \theta_{\max } /^{\circ}$ & $3.248 \leq 2 \theta \leq 54.930$ & $4.50 \leq 2 \theta \leq 37.80$ & $4.32 \leq 2 \theta \leq 36.72$ \\
\hline$\rho(\mathrm{MoK} \alpha) / \mathrm{mm}^{-1}$ & 0.065 & 0.065 & 0.056 \\
\hline Temperature/ K & 123 & 123 & 123 \\
\hline Crystal form & block & block & block \\
\hline Crystal size/ $\mathrm{mm}^{3}$ & $0.45 \times 0.20 \times 0.10$ & $0.70 \times 0.20 \times 0.07$ & $0.30 \times 0.19 \times 0.07$ \\
\hline Crystal color & colorless & colorless & colorless \\
\hline$\#$ of total reflections & 325364 & 136929 & 346893 \\
\hline \# of unique reflections & 64494 & 32632 & 69586 \\
\hline \# of observed reflections & 28127 & 18315 & 18944 \\
\hline$R_{\text {int }}$ & 0.1081 & 0.0613 & 0.1515 \\
\hline$R 1\left(F_{o}\right)$ & 0.1491 & 0.1508 & 0.201 \\
\hline$w R 2\left(F_{\mathrm{o}}^{2}\right)$ & 0.3823 & 0.406 & 0.461 \\
\hline G. O.F. & 1.206 & 1.468 & 1.206 \\
\hline$\#$ of parameters used & 2735 & 2541 & 2140 \\
\hline$\Delta \rho_{\max } / \mathrm{e} \AA^{-3}$ & 1.421 & 1.16 & 1.331 \\
\hline$\Delta \rho_{\min } / \mathrm{e} \AA^{-3}$ & -0.480 & -0.476 & -0.779 \\
\hline$C C D C$ number & 1953695 & 1953696 & 1953697 \\
\hline
\end{tabular}



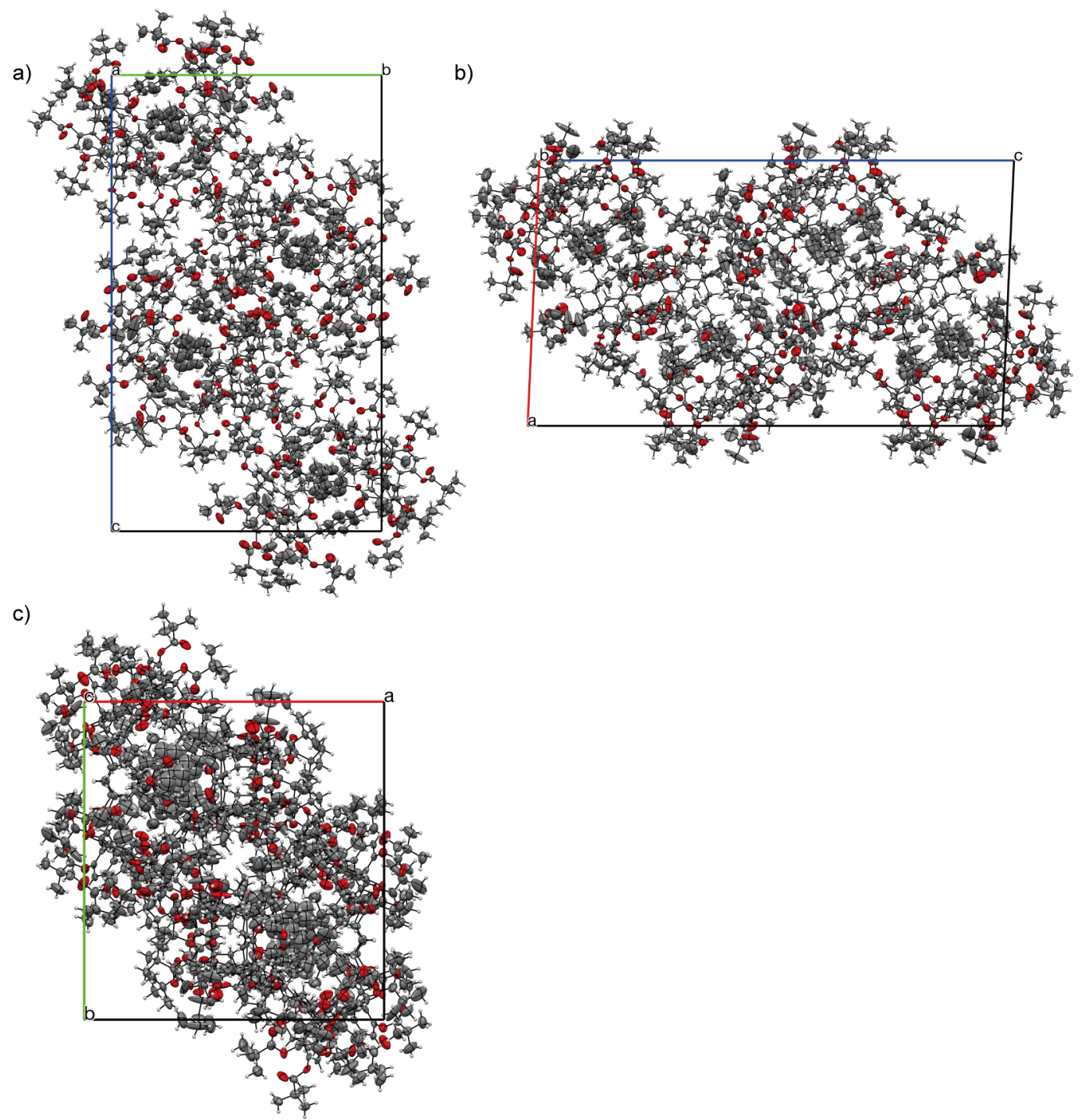

Figure S36. ORTEP drawing of the X-ray crystal structure of 3a. Views along (a) $a-$-, (b) $b$-, and (c) $c$-axes. Ellipsoids are shown at 50\%. (Crystals were obtained by slow diffusion of hexane vapor into the solution in benzene.) 


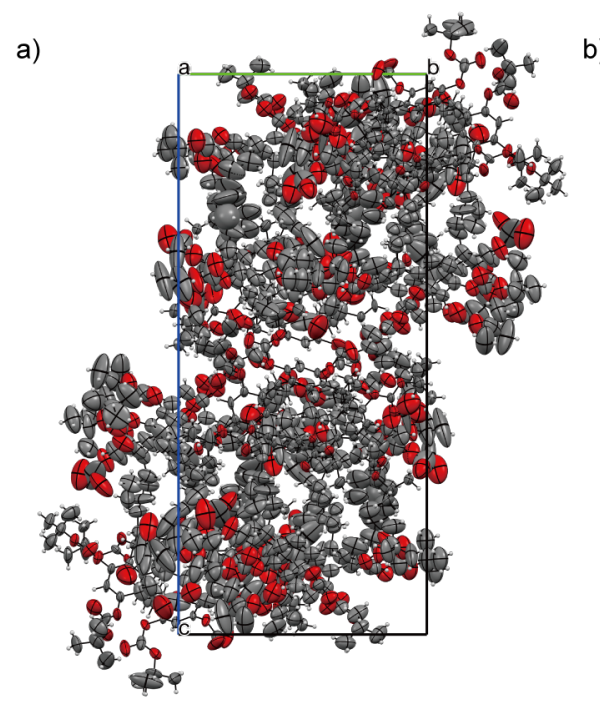

b)

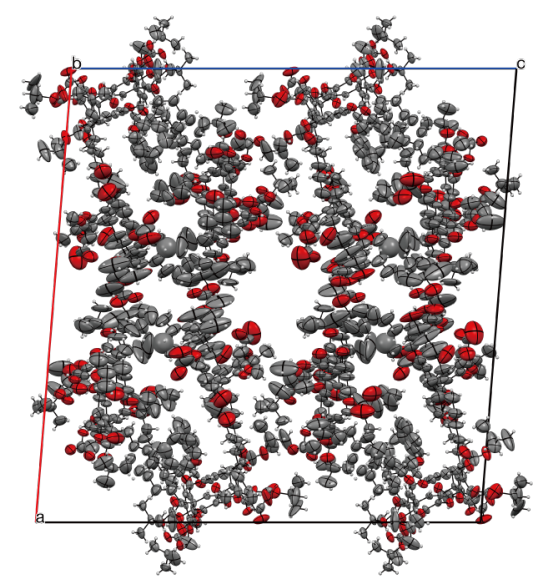

c)

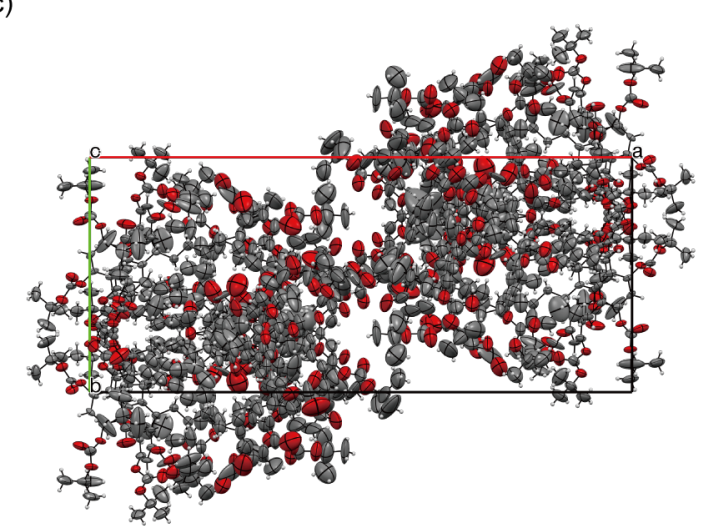

Figure S37. ORTEP drawing of the X-ray crystal structure of $\mathbf{3 b}$. Views along (a) $a-$, (b) $b$-, and (c) $c$-axes. Ellipsoids are shown at 50\%. (Crystals were obtained by slow diffusion of hexane vapor into the solution in benzene.) 
a)

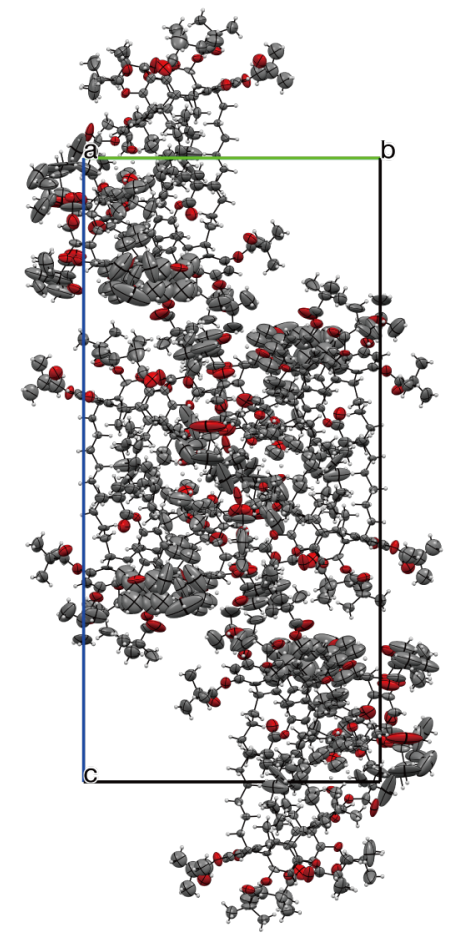

c)

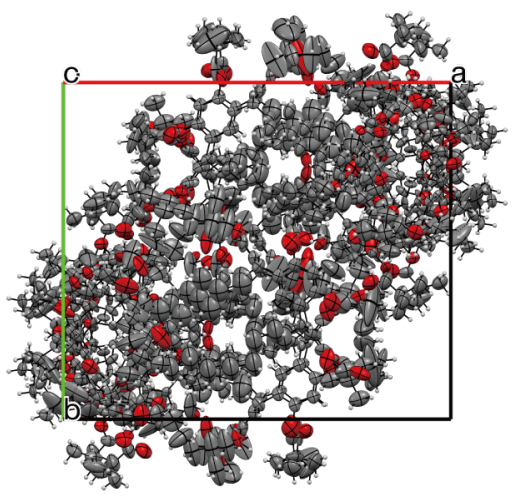

b)

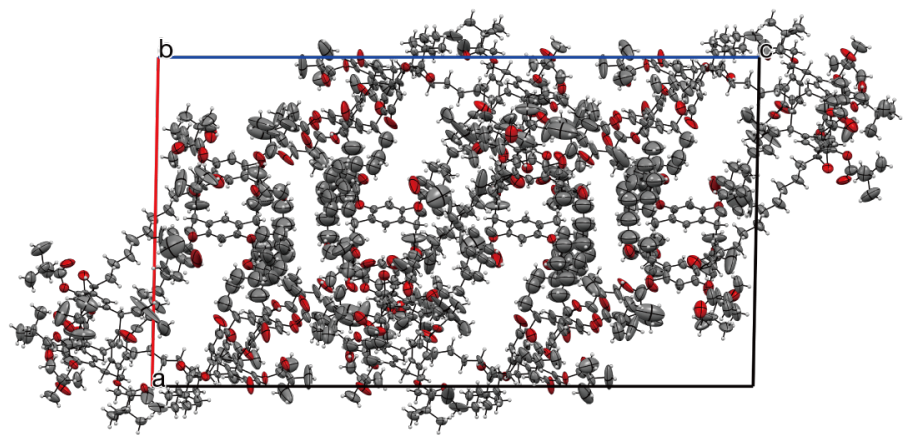

Figure S38. ORTEP drawing of the X-ray crystal structure of 3c. Views along (a) $a-$, (b) $b$-, and (c) $c$ axes. Ellipsoids are shown at 50\%. (Crystals were obtained by slow diffusion of hexane vapor into the solution in benzene.) 
Table S2. Dihedral angles of aliphatic methylene chains in the crystal structure of 3a.

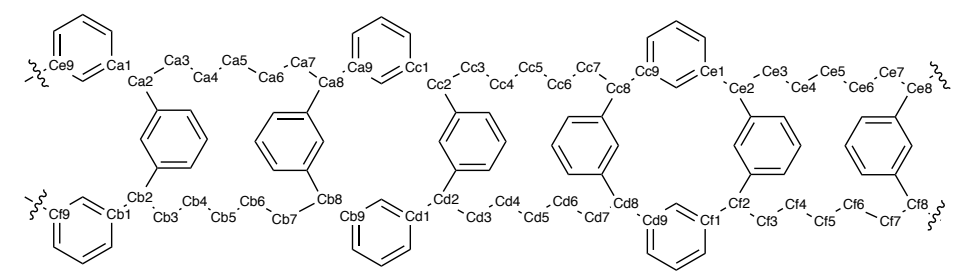

\begin{tabular}{l|rrrrrr}
\hline & $\mathrm{a}$ & $\mathrm{b}$ & $\mathrm{c}$ & $\mathrm{d}$ & $\mathrm{e}$ & $\mathrm{f}$ \\
\hline $\mathrm{C}_{1}-\mathrm{C}_{2}-\mathrm{C}_{3}-\mathrm{C}_{4}$ & 166.21 & -161.32 & 162.01 & -166.93 & 160.01 & -167.09 \\
$\mathrm{C}_{2}-\mathrm{C}_{3}-\mathrm{C}_{4}-\mathrm{C}_{5}$ & -178.26 & 177.27 & -169.67 & 177.95 & -174.34 & 176.35 \\
$\mathrm{C}_{3}-\mathrm{C}_{4}-\mathrm{C}_{5}-\mathrm{C}_{6}$ & 171.14 & -166.91 & 169.15 & -169.44 & 168.20 & -172.80 \\
$\mathrm{C}_{4}-\mathrm{C}_{5}-\mathrm{C}_{6}-\mathrm{C}_{7}$ & -168.20 & 168.88 & -177.44 & 168.27 & -174.51 & 169.84 \\
$\mathrm{C}_{5}-\mathrm{C}_{6}-\mathrm{C}_{7}-\mathrm{C}_{8}$ & 176.94 & -177.69 & 177.32 & -171.57 & 175.84 & -176.12 \\
$\mathrm{C}_{6}-\mathrm{C}_{7}-\mathrm{C}_{8}-\mathrm{C}_{9}$ & -161.28 & 163.55 & -165.64 & 158.09 & -164.21 & 163.10
\end{tabular}

Table S3. Dihedral angles of aliphatic methylene chains in the crystal structure of $\mathbf{3 b}$.

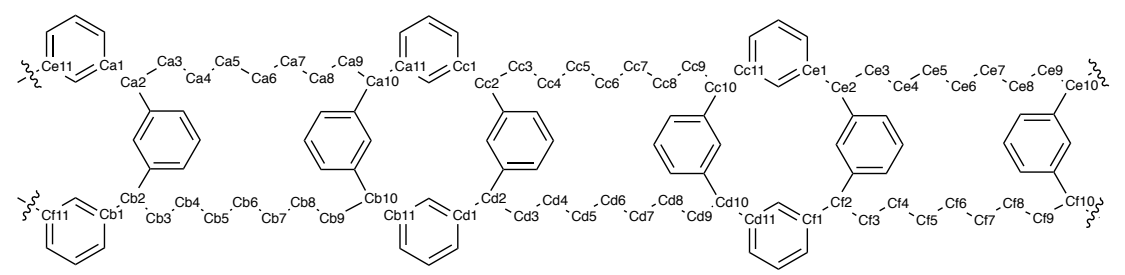

\begin{tabular}{|c|c|c|c|c|c|c|}
\hline & a & b & c & d & e & f \\
\hline $\mathrm{C}_{1}-\mathrm{C}_{2}-\mathrm{C}_{3}-\mathrm{C}_{4}$ & 152.60 & -170.87 & 167.37 & -165.53 & 169.70 & -63.52 \\
\hline $\mathrm{C}_{2}-\mathrm{C}_{3}-\mathrm{C}_{4}-\mathrm{C}_{5}$ & 177.68 & 139.62 & $\begin{array}{l}-73.78 \\
178.62\end{array}$ & 58.65 & -176.45 & -176.66 \\
\hline $\mathrm{C}_{3}-\mathrm{C}_{4}-\mathrm{C}_{5}-\mathrm{C}_{6}$ & 26.79 & 46.38 & $\begin{array}{r}-132.76 \\
172.91\end{array}$ & 152.13 & -70.47 & -170.94 \\
\hline $\mathrm{C}_{4}-\mathrm{C}_{5}-\mathrm{C}_{6}-\mathrm{C}_{7}$ & 177.93 & 127.54 & $\begin{array}{l}-46.94 \\
-72.85\end{array}$ & 60.13 & 170.65 & 179.95 \\
\hline $\mathrm{C}_{5}-\mathrm{C}_{6}-\mathrm{C}_{7}-\mathrm{C}_{8}$ & 112.20 & 164.83 & $\begin{array}{l}-155.97 \\
-158.42\end{array}$ & 171.93 & -179.69 & -58.80 \\
\hline $\mathrm{C}_{6}-\mathrm{C}_{7}-\mathrm{C}_{8}-\mathrm{C}_{9}$ & 71.70 & 31.94 & $\begin{array}{r}-91.31 \\
75.38\end{array}$ & 69.24 & 167.39 & -155.10 \\
\hline $\mathrm{C}_{7}-\mathrm{C}_{8}-\mathrm{C}_{9}-\mathrm{C}_{10}$ & 128.13 & 174.13 & 178.84 & 179.23 & 68.37 & -42.51 \\
\hline $\mathrm{C}_{8}-\mathrm{C}_{9}-\mathrm{C}_{10}-\mathrm{C}_{11}$ & -164.96 & 166.15 & -165.13 & 163.95 & -160.75 & 164.21 \\
\hline
\end{tabular}


Table S4. Dihedral angles of aliphatic methylene chains in the crystal structure of 3c.

\begin{tabular}{|c|c|c|c|c|c|c|}
\hline & a & $\mathrm{b}$ & C & $d$ & e & $f$ \\
\hline $\mathrm{C}_{1}-\mathrm{C}_{2}-\mathrm{C}_{3}-\mathrm{C}_{4}$ & 168.53 & -164.37 & 160.32 & -167.33 & 166.40 & -170.24 \\
\hline $\mathrm{C}_{2}-\mathrm{C}_{3}-\mathrm{C}_{4}-\mathrm{C}_{5}$ & -178.59 & 160.32 & 172.59 & 178.42 & -155.98 & 169.58 \\
\hline $\mathrm{C}_{3}-\mathrm{C}_{4}-\mathrm{C}_{5}-\mathrm{C}_{6}$ & -177.85 & 66.57 & 169.75 & -178.33 & $\begin{array}{r}33.26 \\
-61.46\end{array}$ & -59.41 \\
\hline $\mathrm{C}_{4}-\mathrm{C}_{5}-\mathrm{C}_{6}-\mathrm{C}_{7}$ & 175.42 & 173.15 & -87.51 & -177.30 & $\begin{array}{r}-102.95 \\
76.61\end{array}$ & 174.23 \\
\hline $\mathrm{C}_{5}-\mathrm{C}_{6}-\mathrm{C}_{7}-\mathrm{C}_{8}$ & -19.91 & -176.47 & 163.39 & 175.45 & $\begin{array}{r}156.57 \\
33.57\end{array}$ & -81.69 \\
\hline $\mathrm{C}_{6}-\mathrm{C}_{7}-\mathrm{C}_{8}-\mathrm{C}_{9}$ & 172.53 & 170.61 & $\begin{array}{r}-162.05 \\
-84.06\end{array}$ & 178.43 & $\begin{array}{l}-137.94 \\
-158.82\end{array}$ & -168.59 \\
\hline $\mathrm{C}_{7}-\mathrm{C}_{8}-\mathrm{C}_{9}-\mathrm{C}_{10}$ & -104.58 & -178.38 & $\begin{array}{l}148.43 \\
172.28\end{array}$ & 177.83 & $\begin{array}{r}-84.81 \\
-71.85\end{array}$ & -63.36 \\
\hline $\mathrm{C}_{8}-\mathrm{C}_{9}-\mathrm{C}_{10}-\mathrm{C}_{11}$ & -43.39 & 161.02 & $\begin{array}{l}40.28 \\
63.17\end{array}$ & -167.60 & -92.84 & 178.05 \\
\hline $\mathrm{C}_{9}-\mathrm{C}_{10}-\mathrm{C}_{11}-\mathrm{C}_{12}$ & -168.77 & -174.30 & $\begin{array}{l}162.32 \\
148.61\end{array}$ & -179.17 & 68.65 & -159.53 \\
\hline $\mathrm{C}_{10}-\mathrm{C}_{11}-\mathrm{C}_{12}-\mathrm{C}_{13}$ & -167.87 & -53.43 & $\begin{array}{r}178.37 \\
72.77\end{array}$ & 171.54 & -177.30 & 158.40 \\
\hline
\end{tabular}

